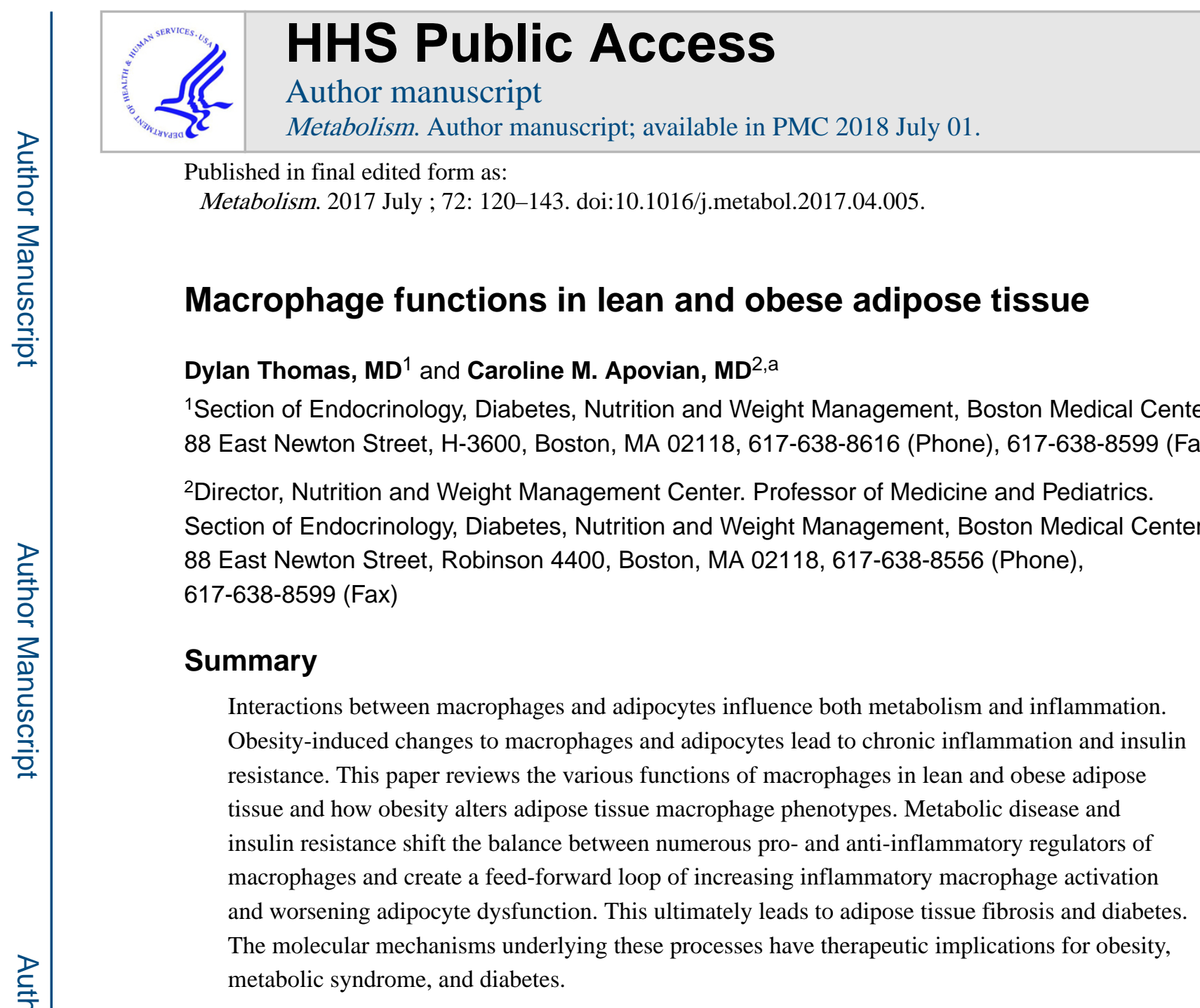

\title{
Introduction
}

Macrophages are professional mononuclear phagocytes that maintain tissue homeostasis and function by scavenging debris, pathogens, and apoptotic or necrotic cells. Circulating monocytes differentiate into diverse resident macrophages found in almost all tissues including spleen, liver (Kupffer cells), lung (alveolar macrophages), brain (microglia), bone (osteoclasts and marrow macrophages), eye, lymph nodes, intestines, and fat (adipose tissue macrophages). Each macrophage phenotype has a specialized function and maintains the local tissue microenvironment and inflammatory tone. Even within a single organ, macrophages can display heterogeneous phenotypes as has been demonstrated within adipose tissue macrophages (ATM).

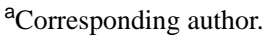

Publisher's Disclaimer: This is a PDF file of an unedited manuscript that has been accepted for publication. As a service to our customers we are providing this early version of the manuscript. The manuscript will undergo copyediting, typesetting, and review of the resulting proof before it is published in its final citable form. Please note that during the production process errors may be discovered which could affect the content, and all legal disclaimers that apply to the journal pertain.

Disclosure Statement: Dylan Thomas discloses no conflicts (DT).

Author contributions: Dr. Dylan Thomas performed the review of the literature, summarized and interpreted results, drafted the manuscript, and approved the final version of the manuscript. Dr. Caroline Apovian conceived and designed the review, edited and revised the manuscript, and approved the final version of the manuscript.
} 
Adipose tissue, previously considered a simple sink for calories, is now recognized as a dynamic organ with an intricate vasculature and innervation that is a key driver of metabolic flexibility. Lean and obese adipose tissue have different associated macrophage populations that will be reviewed in detail. Adipocytes secrete numerous paracrine, endocrine hormones, and adipokines (adipose cytokines) that regulate systemic metabolism and local and systemic inflammation ${ }^{1,2}$. Traditionally, regulation of the transformation and oxidation of nutrients in adipocytes and other metabolic tissues has been considered as separate and distinct from the immune system's role in defense from pathogens. However, we now know that both pathogens and overnutrition cause chronic cellular stress that activates shared signaling pathways.

Excess calories induce intracellular changes in reduction (redox) potential and oxidative stress and cause endoplasmic reticulum (ER) stress in hepatocytes, adipocytes, and hypothalamic neurons ${ }^{3}$. Hepatocytes interact with Kuppfer cells by secreting paracrine hormones that affect lipid metabolism and hepatic insulin sensitivity. Overnutrition leads to Kuppfer cell activation, chronic inflammation, hepatic steatosis and eventual steatohepatitis and cirrhosis. Similarly, in the vascular intima, overnutrition induced hyperlipidemia leads to oxidized LDL formation and uptake in macrophages leading to foam cell formation and vascular inflammation. The crosstalk between metabolism and inflammation is also demonstrated by immunomodulatory corticosteroids that also have strong effects on host protein and carbohydrate metabolism. This has clinical relevance since immunosuppressant medications used after solid organ transplantation are associated with an increased risk of diabetes.

Metaflammation is the process whereby excess nutrients promote chronic low-grade inflammation ${ }^{4}$. Unlike the acute, intense, and rapidly resolving inflammation in response to infection and injury, low-grade chronic tissue stress is associated with a physiologic adaptive immune response called para-inflammation ${ }^{5}$. Para-inflammation affects recruitment of monocytes and tissue macrophages, which are at the center of the interaction between metabolism and inflammation. Dysregulation of chronic para-inflammation may contribute to disease progression. For example, chronic low-grade inflammation causes insulin resistance, which leads to the transition from metabolically healthy obesity to metabolic syndrome. The metabolic syndrome is not a purely metabolic disorder, but also a chronic systemic inflammatory syndrome characterized by elevated serum inflammatory cytokines including tumor necrosis factor- $a$ (TNF- $a$ ) and macrophage infiltration into adipose tissue.

Hence, macrophages are central to immunometabolism ${ }^{6}$, obesity associated tissue remodeling, and the development of adiposity-based chronic diseases comorbidities including chronic systemic inflammation, metabolic syndrome, obesity-related insulin resistance (OIR), non-alcoholic fatty liver disease, and type 2 diabetes (T2D).

\section{Scope of review}

This review will cover the roles of macrophages in lean and obese adipose tissue, in adipose tissue remodeling during the development of obesity, and the potential of 
immunomodulatory therapies to control chronic inflammation of obesity and metabolic syndrome.

\section{Methods}

We searched PubMed/MEDLINE and clinicaltrials.gov for English articles and relevant clinical trials with the search terms: macrophage, inflammation, adipose, and obesity from 1965 to March 2017. We selected pertinent publications from the last 15 years but did not exclude high impact older papers. We reviewed the references from key papers to identify additional articles. Reviews are cited to provide readers with more details and references than is possible here.

After reviewing macrophage classification systems, we examine macrophage functions in lean adipose tissue, and their role in the pathways that control inflammation, energy expenditure, and insulin sensitivity. We review how obesity leads to oxidative stress and skews the balance between pro- and anti-inflammatory macrophages leading to insulin resistance, hypoxia, and inflammasome activation. Next, we discuss how this leads to altered adipokine secretion, formation of crown-like structures (CLS), activation of other lymphocyte subsets and fibrotic remodeling. Finally, we review the changes in adipose tissue with T2D and after bariatric surgery and consider the therapeutic implications of these findings.

\section{Macrophages are broadly classified as M1 or M2}

Just as CD4+ T cells have been classified according to their distinct cytokine signatures and functions as Th1/Th2, macrophages have traditionally been categorized into two distinct and mutually exclusive activation states: classical (M1) and alternative (M2). M1 activation occurs in response to molecules derived from bacterial infections such as lipopolysaccharide (LPS) and interferon- $\gamma$ (IFN- $\gamma$ ). M1 macrophages are highly inflammatory and express the integrin a-chain Cd11c. M1 macrophages also express CD11b and F4/80 markers in mice, hence they are also called "triple" positive. M2 macrophages express CD11b and F4/80 but do not express $\mathrm{Cd} 11 \mathrm{c}$, hence they are also called "double" positive. M2 activation occurs in response to parasites and their associated cytokines interleukin (IL)-4 and IL-13. M2 macrophages promote tissue repair and inhibit M1 macrophages. A large number of alternative cell-surface markers have also been identified to distinguish M1 and M2 macrophages in mice and humans ${ }^{7}$.

Macrophages can be activated by a variety of endogenous and exogenous stimuli and serve a range of functions across different tissues. Therefore, the dichotomy between M1 and M2 macrophages is an oversimplification ${ }^{8}$. Newer classification systems organize macrophages along a continuum (M1, M2a, M2b, M2c) ${ }^{9}$ or between three primary groupings based on function (host defense, wound healing, and immune regulation) with various combinations of these forming a spectrum of activation ${ }^{10}$ (Figure 1). While imperfect and still evolving, these classification systems have been widely used in the literature to characterize tissue macrophages. A review macrophage functions in lean and obese adipose tissue follows. 


\section{Macrophage functions in lean tissue}

In lean subcutaneous adipose tissue, about $10 \%$ of the cells stain positive for the macrophage marker CD68 in humans or F4/80 in mice ${ }^{11}$. Macrophages are important cells for host defense and serve numerous functions including pro- and anti-inflammatory responses ${ }^{12}$. In lean tissue, macrophages work in efferocytosis (removal of dying or dead cells), lipid buffering, angiogenesis, and apoptotic cell clearance ${ }^{13}$. The complex crosstalk between adipocytes and macrophages is demonstrated by the ability of preadipocytes (adipose progenitor cells) to differentiate into macrophages ${ }^{14}$ and possibly also macrophages to differentiate into preadipocytes ${ }^{15}$.

Another important function of macrophages is regulation of iron flux. Adipocytes, macrophages, and mitochondria all depend on iron for proper functioning. Macrophages express the receptor for haptoglobin-hemoglobin CD163 and also secrete the acute-phase reactant hepcidin. Iron is important for adipogenesis. With obesity, adipocytes become iron overloaded. The association of metabolic disease and iron overload has been called dysmetabolic iron overload syndrome and has been reviewed elsewhere ${ }^{16}$.

\subsection{Macrophages regulate the immune response}

Macrophages are key to the innate immune response to pathogens. Macrophages function as antigen presentation cells and regulate adipose tissue $\mathrm{T}$ cells ${ }^{17}$. Upon activation, macrophages release cytokines and chemokines that initiate an inflammatory response. The suppressor of cytokine signaling (SOCS) family regulates this response via feedback inhibition targeting the Janus kinase (JAK) pathway, a signaling cascade that transduces signals from cytokines and regulates cell proliferation and insulin sensitivity. Toll-like receptors (TLR) are evolutionarily conserved pathogen-associated molecular pattern receptors that recognize potential pathogens and mount an immune response.

MicroRNA (miRNA) are small non-coding RNA molecules that regulate gene expression by binding to messenger RNA. miRNA-155 is released by inflammatory macrophages in response to danger signals such as TLR ligands and LPS ${ }^{18}$. miRNA-155 represses SOCS leading to JAK signaling and increased inflammation.

Pro-inflammatory miRNA from inflammatory macrophages such as this are balanced by anti-inflammatory cytokines such as protectin. Protectin is synthesized by M2 macrophages and is involved with the resolution of inflammation and tissue healing ${ }^{19}$. M2 macrophages express lower levels of inflammatory cytokines and higher levels anti-inflammatory cytokines such as IL-10, IL-1RA. M2 macrophages also secrete transforming growth factor (TGF)- $\beta$ which promotes collagen expression and fibrosis but also have a crucial role in tissue repair ${ }^{20}$ (Table 1).

\subsection{Macrophages regulate insulin sensitivity, adipogenesis, and angiogenesis}

Macrophages regulate adipogenesis and angiogenesis ${ }^{21}$ in response to environmental, nutritional, and physical stimuli through interactions with preadipocytes ${ }^{22}$. Macrophages secrete platelet-derived growth factor (PDGF), which promotes preadipocyte survival leading to adipose tissue hyperplasia and maintenance of insulin sensitivity ${ }^{23}$. Conversely, 
M1 macrophages induce insulin resistance, which is reviewed below. In lean tissue, M2 macrophages interact with preadipocytes by releasing factors that promote survival and maintain adequate angiogenesis ${ }^{24}$. We review below how obesity is associated with altered angiogenesis with subsequent adipose tissue hypoxia and fibrosis.

Peroxisome proliferator activated receptor (PPAR) is a family of nuclear proteins that function as transcription factors that regulate adipocyte gene expression and functions. The three types of PPAR will be discussed and include PPAR- $a$, PPAR- $\delta$, and PPAR- $\gamma$ (Table 2 ). PPAR- $\gamma$ is a nuclear hormone receptor that controls systemic fatty acid metabolism and mitochondrial biogenesis. PPAR- $\gamma$ promotes primary human monocytes to differentiate into an M2 phenotype ${ }^{25}$. M2 macrophages maintain insulin sensitivity by secreting the antiinflammatory cytokine IL- $10^{26}$. Macrophage-specific deletion of the PPAR- $\gamma$ receptor impairs M2 macrophage activation and decreases expression of genes involved in oxidative phosphorylation in liver and muscle tissue, which is associated with decreased insulin sensitivity in these tissues ${ }^{27}$. The PPAR proteins have many other important effects on adipose tissue that are reviewed below.

Thiazolidinediones (TZD) are a class of medications used to treat T2D which act as PPAR- $\gamma$ agonists and include rosiglitazone and pioglitazone. The combination of rosiglitazone and dexamethasone inhibits ATM accumulation in murine epididymal fat ${ }^{28}$. Similarly, pioglitazone in humans reduces macrophage chemoattractant factors after 10 and 21 days, reduces adipose tissue macrophage content by $69 \%$ after 21 days, and improves insulin sensitivity ${ }^{29}$. Pioglitazone induced apoptosis in subcutaneous adipose tissue macrophages in humans with impaired glucose tolerance, but in this study M1 and M2 macrophages were not distinguished ${ }^{30}$. Pioglitazone is still clinically used for the treatment of T2D but rosiglitazone was withdrawn from the market due to increased risk of myocardial infarction. Unfortunately, TZD are associated with weight gain, edema, increased risk of bone fractures, and possibly increased risk of bladder cancer, which limits their clinical attractiveness for the treatment of T2D. The use of other medications as modulators of inflammation and macrophage polarization is reviewed below.

Macrophages respond to several inflammatory and metabolic pathways and regulate insulin sensitivity and adipose tissue and remodeling. We now focus on the anti-inflammatory mediators of ATM.

\subsection{Anti-inflammatory regulators of macrophages}

Fatty acid binding proteins (FABPs) are lipid chaperones involved in lipid metabolism that are altered in obesity. The FABP aP2 is induced by PPAR- $\gamma$ and by oxidized LDL in human THP-1 macrophages ${ }^{31}$. Macrophages deficient in aP2 have lowered inflammatory cytokine expression and reduced atherosclerosis in a model of severe hypercholesterolemia ${ }^{32,33}$. Mice deficient in aP2 have an altered macrophage inflammatory response and exhibit an uncoupling of the usual association between obesity and insulin resistance by remaining insulin sensitive despite developing HFD-induced obesity ${ }^{34}$. Mice lacking both aP2 and another FABP mal1 are resistant to HFD induced obesity and insulin resistance ${ }^{35}$. These studies provide insight into the complex interactions between the metabolic and inflammatory response to HFD and its implications for atherosclerosis. 
There are at least three distinct pathways that serve as anti-inflammatory regulators of macrophages: PPAR- $\delta$, eisonoids, and anti-inflammatory lipids.

PPAR- $\delta$ is a nuclear hormone receptor that regulates arginase-1, an enzyme expressed by M2 macrophages with anti-inflammatory and anti-fibrotic actions. PPAR- $\delta$ is required for the alternative macrophage activation by the unsaturated fatty acid oleic acid, and protects against diet-induced insulin resistance and obesity in mice ${ }^{36}$. PPAR- $\delta$ is induced when macrophages engulf apoptotic cells and enhances the production of opsonins, which facilitate the clearance of apoptotic debris by macrophages ${ }^{37}$. There are few PPAR- $\delta$ agonists that are clinically used in humans. Bezafibrate is not approved for use in the United States but is approved for the treatment of dyslipidemia in Canada. Several PPAR- $\delta$ agonists are in clinical development. For example, the novel PPAR- $\delta$ agonist PYPEP improved lipids, lowered chemokine (C-C motif) ligand 2 (CCL2) and suppressed atherosclerotic lesion progression in mice ${ }^{38}$. CCL2, also known as monocyte chemoattractant protein-1 (MCP-1), is a cytokine secreted by macrophages, adipocytes, and many other cell types that recruits inflammatory cells to sites of tissue injury or inflammation. CCR2 is a receptor for CCL2 and other cytokines that is present on monocytes, neutrophils, neuronal cells, and macrophages. The regulation and inflammatory consequences of CCL2 are reviewed later on.

Eicosanoids are lipid mediators of inflammation. Mice overexpressing ALOX5AP have increased lipoxin A4 production and reduced mRNA levels of the macrophage markers F4/80 and IL-6 in epididymal white adipose tissue ${ }^{39}$. Lipoxin A4 promotes ABCA expression and cholesterol efflux from macrophages and increases high-density lipoprotein (HDL) levels. HDL has antioxidant and anti-inflammatory properties ${ }^{40}$. Prostaglandin D2 is another eicosanoid produced in macrophages that promotes M2 differentiation and is positively correlated with insulin sensitivity ${ }^{41}$.

Branched fatty acid esters of hydroxy fatty acids (FAHFA) were recently identified as antiinflammatory regulatory molecules of ATM that are reduced in insulin-resistant states. Treatment of HFD-fed mice with FAHFA decreased the percentage of TNF- $\alpha$ and IL-1 $\beta$ positive macrophages in perigonadal white adipose tissue ${ }^{42}$. For a review of the antiinflammatory effects of FAHFA, see ${ }^{43}$. FAHFAs decrease macrophage activation in vitro following exposure to LPS and IFN- $\gamma$ and hold promise as potential therapies for inflammatory and metabolic diseases ${ }^{44}$.

\subsection{Cold, exercise, and eosinophils induce M2 catecholamine production and beige fat}

Brown adipose tissue comprises a minority of the adipose tissue mass in humans and functions to maintain body temperature via adaptive thermogenesis. Uncoupling Protein 1 (UCP-1) mediates thermogenesis and is increased in brown adipocytes. Beige adipose cells are dispersed throughout adipose tissue and have low basal UCP-1 expression but can be activated by cold or beta-adrenergic stimulation by catecholamines into a state with high UCP-1 expression and respiration ${ }^{45}$. These discoveries led to research into molecules that can activate beige adipocytes or achieve white to brown fat transdifferentiation of visceral adipocytes. 
Exposure to cold induces macrophage infiltration to cold-stressed subcutaneous white adipose tissue via CCR2. Cold activates a thermogenic circuit consisting of eosinophils and M2 macrophages that regulate local production of catecholamines and increase beige fat mass ${ }^{46}$. M2 macrophages are induced by IL-4, which is predominantly secreted by eosinophils in lean mice ${ }^{47}$. M2 macrophages activated by cold exposure upregulate thermogenic gene expression in brown adipose tissue and promote fatty acid mobilization in white adipose tissue ${ }^{48}$. Meteorin-like is a novel hormone secreted in response to exercise and cold exposure that stimulates eosinophil IL-4 release and alternative activation of macrophages in adipose tissue. Meteorin-like is required for physiologic adaptation to cold in mice ${ }^{49}$. The insulin-sensitizing effects of meteorin-like occur through activation of the PPAR- $\gamma$ pathway ${ }^{50,51}$.

Exposure to cold also stimulates secretion of the adipokine adiponectin, which has antiinflammatory and insulin sensitizing properties. The receptor for adiponectin is expressed on macrophages. Adiponectin production is stimulated by PPAR- $\gamma$ ligands and promotes M2 macrophage polarization ${ }^{52}$. Adiponectin also induces browning of subcutaneous adipose tissue via Akt-mediated M2 macrophage proliferation ${ }^{53}$.

These findings have translational implications. For example, chronic helminth infection in mice increases white adipose tissue eosinophils and M2 macrophages and improves glucose uptake and insulin sensitivity ${ }^{54}$. Further studies elucidating the mechanisms behind eosinophil activation and its beneficial metabolic effects are warranted as they may reveal new drug targets. Xanthoangelol is a phytochemical that attenuates LPS induced c-Jun Nterminal kinase (JNK) phosphorlyation in macrophages, lowers macrophage infiltration into subcutaneous white adipose tissue, improves glucose tolerance, and increases UCP-1 expression in diet-induced obesity (DIO) mice ${ }^{55}$ but has not advanced to clinical trials in humans to date. The cannabinoid receptor type 1 antagonist rimonabant was withdrawn from the market due to safety concerns about serious psychiatric side effects. However, cannabinoid receptor type 2 receptor polymorphisms are associated with obesity and the cannabinoid receptor type 2 agonist JWH-133 enhanced adipocyte UCP-1 expression (consistent with a browning effect) and hindered IL-6 release ${ }^{56}$. In addition to these potential candidates for drug development, several other classes of molecules are in clinical trials for obesity modulate brown fat and energy intake and expenditure and have been reviewed ${ }^{57}$.

Macrophages are therefore central to immune regulation of adaptive thermogenesis in beige and brown adipose tissues, which affects energy expenditure ${ }^{58}$.

\subsection{Adipose tissue inflammation regulates energy expenditure}

Whereas adipocytes synthesize and either store or mobilize fatty acids, ATM perform lipophagy (particularly at CLS) followed by intracellular lipolysis. In cell culture, human macrophages take small bites out of adipocytes (a process called trogocytosis), which triggers robust macrophage IL-6 secretion ${ }^{59}$. Paradoxically, obesity is associated with chronic inflammation, but inflammation stimulates energy expenditure and lipolysis. Thus, mice with genetic knockouts of pro-inflammatory cytokines have decreased energy expenditure and develop obesity ${ }^{60}$. Conversely, transgenic mice with elevated NF- $\mathrm{kB}$ have 
elevated TNF- $a$ and IL-6 in adipose tissue and serum, reduced adipogenesis, elevated energy expenditure, and protection from HFD-induced obesity ${ }^{61}$.

The inflammatory cytokine TNF- $a$ is released by M1 macrophages and decreases lipoprotein lipase synthesis and activity ${ }^{62}$. The anti-TNF-a monoclonal antibody ethanercept used in psoriasis may improve insulin sensitivity ${ }^{63}$. However, studies have failed to consistently replicate this finding ${ }^{64,65}$. Body fat increases after starting anti-TNF medications, although it is not clear whether this is mediated by changes in appetite or energy expenditure ${ }^{66}$.

The miRNA-34a is increased in subcutaneous adipose tissue in humans with obesity and targets the soluble IL-6 receptor. miRNA-34a -/- knockout mice are more susceptible to HFD induced weight gain and have increased ATM expression of the anti-inflammatory cytokine IL-10 mRNA ${ }^{67}$. FGF21 is a hormone that enhances fat oxidation and enhances browning of white adipose tissue. Lentiviral mediated downregulation of miR-34a increases FGF21 signaling and reduced adiposity in DIO mice ${ }^{68}$. These discordant results may be reconciled based on tissue specific effects of miR-34a in adipose and muscle, and differences between whole-body knockout compared with lentiviral-mediated repression. The FGF21 genotype affected the changes in central adiposity and body fat composition achieved by energy restricted diets of differing macronutrients composition in POUNDS Lost, a 2-year randomized diet intervention trial ${ }^{69}$. This may be mediated by FGF21 activation of AMP-activated protein kinase (AMPK) and SIRT1 (an anti-inflammatory deacetylase that stimulates autophagy), which inhibits macrophage-mediated inflammation ${ }^{70}$. The metabolic and inflammatory effects of AMPK are reviewed next and autophagy and the clinical implications of these findings are reviewed later on.

\subsection{AMPK is a metabolic sensor that regulates macrophages and inflammation}

AMPK is an enzyme that is activated by phosphorylation in response to exercise and other stimuli that activates genes involved in fatty acid oxidation in human macrophages ${ }^{71}$. Macrophages AMPK activity is increased upon stimulation with IL-10 and decreased upon stimulation with LPS ${ }^{72}$. Activation of AMPK in macrophages increases SIRT1 activity and inhibits LPS or free fatty acid (FFA) induced NF- $\kappa$ B activation ${ }^{73}$. Wild-type mice that receive a bone marrow transplant from AMPK deficient mice and are fed a HFD develop M1 macrophage polarization with enhanced secretion of TNF- $a$ and IL- 6 in response to the saturated fatty acid palmitate ${ }^{74}$. AMPK upregulates GLUT4 expression in cardiomyocytes, enhances mitochondrial biogenesis, and inhibits fatty acid synthesis ${ }^{75}$. IL-6 is released by skeletal muscle during exercise and activates AMPK in muscle and adipose tissue ${ }^{76}$. IL-6 is a cytokine that has either pro-inflammatory or anti-inflammatory properties depending on whether it binds to its membrane receptor (leading to activation of the JAK pathway) or to its soluble receptor ${ }^{77}$. Macrophage AMPK activity maintains M2 polarization, mitochondrial function, and inhibits the NLRP3 inflammasome, an intracellular structure that promotes the generation of inflammatory cytokines ${ }^{78,79}$. Further, the AMPK activator metformin significantly attenuated monocyte-to-macrophage differentiation and inhibited plaque formation in ApoE knockout mice ${ }^{80}$. 
From these data, it is clear that AMPK has important metabolic and anti-inflammatory effects. Activators of AMPK include metformin, TZDs, glucagon-like peptide-1 (GLP-1) agonists, dipeptidyl peptidase-4 (DPP-4) inhibitors, salicylates, resveratrol, and adiponectin and there are many others which have been recently reviewed ${ }^{81}$. We now focus on how DPP-4 inhibitors and GLP-1 agonists may affect macrophage function and adipose tissue.

DPP-4 is an enzyme expressed on the surface of adipocytes, endothelial cells, T cells, and M1 macrophages, which degrades a variety of peptides and chemokines including GLP-1 and Neuropeptide $\mathrm{Y}$. The stress hormone Neuropeptide $\mathrm{Y}$ is released by macrophages in adipose tissue where it has anti-inflammatory effects ${ }^{82}$. DPP-4 can also be released from the cell surface and its soluble form is considered an adipokine. GLP-1 is a metabolic hormone that augments glucose-stimulated insulin secretion and may also have anti-inflammatory and cardioprotective actions ${ }^{83}$. GLP-1 may also enhance autophagy and GLP-1 agonists are discussed further in section 3.2. By degrading these hormones, DPP-4 may enhance inflammation and hence DPP-4 inhibitors are hypothesized to have anti-inflammatory effects.

Indeed, DPP-4 inhibitors (including vildagliptin, linagliptin, anagliptin, and sitagliptin) are used for the treatment of T2D and have been show to have anti-inflammatory effects in addition to their glucose lowering effects. Soluble DPP-4 increases the expression of TLR-4 and amplified inflammatory cytokine production in murine macrophage cells and these effects could be inhibited by vildagliptin ${ }^{84}$. Linagliptin decreases M1 macrophages and increases M2 macrophages in adipose tissue and liver in mice on $\mathrm{HFD}^{85}$. Anagliptin reduced gene expression of TNF- $a$ and IL-6 in the carotid arteries of cholesterol-fed rabbits and reduced macrophage accumulation and plaque formation on the coronary arteries ${ }^{86}$. Sitagliptin decreases serum inflammatory markers (TNF-a, CRP, IL-6) and increase antiinflammatory IL-10 in Japanese patients with $\mathrm{T}_{2} \mathrm{D}^{87}$. A randomized controlled noninferiority trial with 14,671 patients with T2D showed that adding sitagliptin to usual care did not increase risk of major adverse events ${ }^{88}$. It is currently unknown whether these antiinflammatory effects can lead to clinically meaningful macrovascular outcomes for patients with T2D.

We have reviewed several of the anti-inflammatory hormones and pathways that decrease macrophage driven inflammation with downstream effects on oxidative stress and metabolism. We review the opposing pro-inflammatory molecules that upregulate macrophage-driven inflammation next.

\section{Macrophage and adipocyte dysfunction in obese adipose tissue}

\subsection{Obesity and oxidative stress alter adipose tissue macrophage polarization leading to adipocyte dysfunction}

Macrophages are the numerically and functionally dominant immune cell in adipose tissue and display tremendous heterogeneity in their functions reflecting their local metabolic and immune microenvironments. In a landmark paper in 2003, mice and humans with obesity were reported to have increased ATM, which correlated with their degree of adiposity ${ }^{11}$. This led to the concept that adipose tissue can recruit additional macrophages in response to 
stimuli. Indeed, abdominal visceral fat tissue area was the most significant predictor of both visceral and subcutaneous macrophage infiltration in women ${ }^{89}$. We now review the mechanisms whereby obesity leads to ATM infiltration.

Obese mice on a HFD develop a novel population of classically activated M1 macrophages in their adipose tissue, increased inflammatory gene expression, and decreased antiinflammatory IL-10 $0^{90}$. These mice have an increased ratio of M1 to M2 macrophages in adipose tissue due to M1 macrophage infiltration that is dependent on dendritic cells ${ }^{91}$. The obesity-driven events initiating inflammation and the transition of ATM from M2 to M1, which then recruit $\mathrm{T}$ cells have been recently reviewed ${ }^{92,93}$. Aging is associated with similar changes in visceral adipose tissue in mice including $\mathrm{T}$ cell infiltration and a shift towards M1 polarization ${ }^{94}$. These changes may be mediated by cell adhesion molecules including intercellular adhesion molecule (ICAM-1) and vascular cell adhesion molecule (VCAM-1). ICAM-1 and VCAM-1 mRNA in visceral fat are increased with obesity and are positively associated with CD68 protein levels ${ }^{95}$. This same association is also seen in the kidney where ICAM-1 is also associated with CD68+ macrophage infiltration and ICAM-1 deficiency is protective against diabetic nephropathy in $\mathrm{db} / \mathrm{db}^{\mathrm{mice}} \mathrm{e}^{96}$.

LPS and IFN- $\gamma$ signal the need for production of reactive oxygen species (ROS) and nitric oxide (NO) for killing of pathogens, which induce irreversible mitochondrial dysfunction. M1 macrophages have increased inducible nitric oxide synthase (iNOS) expression, and knockout iNOS -/- mice do not exhibit the significant increase in M1 markers in epididymal white adipose tissue that is seen in wild type mice on $\mathrm{HFD}^{97}$. NO released by macrophages induces mitochondrial dysfunction by suppressing PGC-1a which can be blocked by rosiglitazone. Pretreatment of macrophages with an iNOS inhibitor reduces mitochondrial dysfunction induced by LPS and IFN- $\gamma$ and shifts macrophages towards M2 polarization ${ }^{98}$. Hence, oxidative stress induces M1 macrophage polarization. Acute overnutrition induces systemic oxidative stress and carbonylation and loss of activity of GLUT4 ${ }^{99}$.

G6PD is an enzyme that shunts glucose into the pentose phosphate pathway and is upregulated in adipose tissues of patients with diabetes and obesity. This pathway produces NADPH, a cofactor for the ROS-producing enzyme NADPH oxidase. In humans, fat accumulation increases ROS production by dysfunctional adipose tissue, which increases markers systemic oxidative stress ${ }^{100}$. Nuclear factor kappa-light-chain-enhancer of activated $\mathrm{B}$ cells $(\mathrm{NFKB})$ is an important transcriptional regulator of inflammatory pathways that is activated by ROS, TNF- $\alpha$, LPS, IL- $1 \beta$, the saturated fatty acid palmitate, and TLR receptor ligands.

G6PD-deficient mice on HFD show reduced inflammatory cytokines, improved insulin sensitivity, and reduced CLS ${ }^{101}$. Conversely, GPD6 overexpression in adipocytes stimulates NADPH oxidase expression, NFKB signaling, and inflammatory cytokines including TNFa, IL-6, CCL2, and resistin and lowered adiponectin ${ }^{102}$. Treatment of obese mice with the inhibitor of NADPH oxidase apocynin significantly decreased ROS production in adipose tissue and improved hyperglycemia, hyperinsulinemia, hepatic steatosis and increased adiponectin and decreased TNF- $a$ expression ${ }^{100}$. Uric acid is elevated in metabolic 
syndrome and induces pro-inflammatory CCL2 expression by redox-dependent signaling via stimulation of NADPH oxidase. Apocynin inhibited the increase in CCL2 secretion by murine adipocytes by uric acid ${ }^{103}$. Hence, inhibitors of ROS production may lower adipose tissue macrophage inflammation.

Another key mediator of the inflammatory response and the redox system is Leukotriene B4 (LTB4). The receptor for LTB4 is expressed on immune cells. LTB4 induces macrophage activation and chemotaxis into adipose tissue ${ }^{104}$. Knockout mice for the gene BLT1 that encodes the receptor for LTB4 have blunted expression of IL-6 and CCL2, an increased ratio of M2:M1 macrophages in adipose tissue, and decreased diet-induced insulin resistance ${ }^{105}$. LTB4 is also a ligand for the transcription factor PPAR- $\alpha$ that upregulates fatty acid $\beta$ oxidation, antioxidant catalase transcription, and LTB4 catabolism ${ }^{106}$. PPAR- $\alpha$ is downregulated by inflammatory transcription factors regulated by NFKB. Activation of PPAR-a by the natural steroid hormone dehydroepiandrosterone-3-sulfate (DHEAS) represses NF $\mathrm{BB}$ signaling, lowers oxidative stress, and reduces inflammatory cytokine production by macrophages ${ }^{107}$. In a randomized clinical trial comparing metformin with a lifestyle intervention, metformin significantly lowered markers of oxidative stress in patients with recently diagnosed $\mathrm{T} 2 \mathrm{D}^{108}$. Indeed, the recent discovery that metformin inhibits mitochondrial glycerophosphate dehydrogenase thereby increasing the cytosolic redox state and increasing cytosolic glutathione is consistent with metformin having an important impact on the cellular redox balance ${ }^{109}$.

Obesity is associated with decreased adiponectin, increased TNF- $a$, increased oxidative stress and $\operatorname{ROS}^{110}$. Oxidative stress leads to decreased circulating adiponectin possibly due to ROS-induced increases in T-cadherin expression which binds adiponectin ${ }^{111}$. AMPK, in addition to the metabolic and anti-inflammatory effects described above, may function in responding to oxidative stress. AMPKa is activated by adiponectin and the novel adipokine C1q/tumour necrosis factor-related protein-3 (CTRP3) which provides protection from hyperglycemia induced oxidative stress, inflammation, and apoptosis in vitro ${ }^{112}$. Both CTRP3 and adiponectin belong to the C1q/TNF superfamily CTRP3 and suppress hepatic gluconeogenesis ${ }^{113}$ and are decreased with obesity ${ }^{114}$. Activation of AMPK by metformin restored ROS-impaired autophagy in senescent cells ${ }^{115}$. The impairment of autophagy will be reviewed further in section 3.3.

Hydrogen sulfide is a gas produced by metabolism cysteine and sulfur-containing proteins that has anti-oxidative and anti-inflammatory properties and inhibits the formation of foam cells from macrophages ${ }^{116}$. Increasing adiposity has been correlated with a reduction in plasma hydrogen sulfide levels which may represent another mechanism whereby obesity causes oxidative stress ${ }^{117}$.

These results suggest that the inflammatory response may activate an antioxidant redox pathway to balance the increased ROS produced by macrophages. Lack of balance between pro- and anti-oxidant pathways leading to oxidative stress may mediate the deleterious effects of HFD on adipocyte function and insulin sensitivity. The large number of pro- and anti-oxidant pathways and pro- and anti-inflammatory regulatory cytokines highlights the redundancy of the immunometabolism. These lists are not complete as we continue to 
discover new molecules associated with the various immune pathways. This redundancy suggests that in vivo inhibition of a single pathway may not be successful and highlights the importance of in vivo study of these pathways. We now review the consequences of adipose tissue macrophage activation.

\subsection{M1 macrophages cause insulin resistance}

Both M1 and M2 macrophages are present in lean and obese adipose tissue. M1 macrophages fail to repolarize into M2 macrophages with IL-4 exposure, whereas M2 macrophages can be repolarized into M1 ${ }^{98}$. M1 macrophages rely on glycolysis whereas M2 macrophages rely on oxidative phosphorylation. This is consistent with their roles since M1 macrophages require rapid energy for intense short bactericidal functions whereas M2 macrophages require a more long-term metabolic source of energy. These findings suggest a metabolic reprogramming of macrophages based on their role and activation state.

Insulin resistance may be adaptive against bacterial infection in order to provide glucose and nutrients to the activated immune system for rapid glycolysis-dependent bacterial killing via respiratory burst ROS production by M1 macrophages. Conversely, helminth-induced Th2 response improves insulin sensitivity, which may be an adaptive response to sequester nutrients and prevent growth of parasites ${ }^{118}$. Since M1 macrophages are dependent on glycolysis, inhibition of glycolysis should decrease M1 activity. Indeed, the glycolytic inhibitor 2-deoxyglucose attenuates the adipocyte release of CCL2 in response to TNF or LPS $^{119}$, again demonstrating the connection between metabolism and inflammation.

The adipokine adipsin is an important regulator of $\beta$ cell function and adipose tissue inflammation via generation of $\mathrm{c} 3 \mathrm{a}$, a potent stimulator of glucose stimulated insulin secretion. Adipsin knockout mice have fewer macrophages and CLS in adipose tissue but develop $\beta$ cell failure on a HFD ${ }^{120}$. Expression of the $c 3$ a receptor in adipocytes and macrophages is increased with HFD feeding and c3a knockout is associated with decreased ATM and improved insulin sensitivity ${ }^{121}$. Hence, this may represent one of the mechanisms whereby HFD leads to CLS and insulin resistance.

Haptoglobin is a plasma protein and an acute phase reactant that binds to free hemoglobin and is upregulated in white adipose tissue in obese mice. Macrophages express the receptor CD163 that binds to the haptoglobin-hemoglobin complex leading to endocytosis. In vitro, haptoglobin in required for normal adipogenesis. It is induced by inflammatory stimuli and repressed by PPAR- $\gamma$. Mice lacking haptoglobin have increased adiponectin and are protected from HFD-induced metabolic dysfunction but have muscle atrophy ${ }^{122}$. Saturated fatty acids increase haptoglobin gene expression in murine adipose tissue ${ }^{123}$. Macrophage inflammatory gene expression in white adipose tissue is upregulated in both genetically obese and DIO mice prior to the development of insulin resistance and can be downregulated by rosiglitazone ${ }^{124}$. HFD fed obese mice develop M1 macrophage infiltration of epididymal fat that peaks after 12 weeks. Three weeks after being switched to a normal chow diet, these insulin-resistant mice lose weight, show improved insulin sensitivity and glucose tolerance, and have decreased inflammatory cytokines and chemokines. At three weeks after the switch back to normal diet, there was no decrease in M1 macrophages in adipose tissue, but at five weeks a decrease towards normal was seen ${ }^{125}$. Hence, even prior to changes in ATM density, 
a normalization in ATM inflammatory cytokines including Galectin-3 and inflammatory gene expression is seen following a switch back to normal chow diet.

In humans the order of events may be different than in mice since insulin resistance may be seen with overfeeding prior to subcutaneous macrophage infiltration. Tam et al. ${ }^{126}$ overfed healthy subjects by $1,250 \mathrm{kcal}$ per day with $45 \%$ fat for 28 days and found that insulin sensitivity assessed by hyperinsulinemic euglycemic clamp was decreased by $11 \%$ and CCL2 and C-reactive protein (CRP) were significantly increased but there were no changes in subcutaneous adipose tissue macrophages, $\mathrm{T}$ cells, or inflammatory gene expression. Visceral adipose tissue ATM was not assessed in this study and may be decreased with weight loss more rapidly than subcutaneous ATM. While the exact sequence of events and mediators is not fully understood, there are clearly a large number of cellular alterations that occur leading to ATM activation in obesity. Just as in mice, adipose tissue inflammation by macrophages and the presence of CLS in humans were similarly associated with metabolic consequences including hyperinsulinemia, insulin resistance, and impaired endotheliumdependent flow-mediated vasodilatation ${ }^{127}$.

Obesity is associated with chronically elevated basal lipolysis and release of FFA in adipose tissue that provides chronic stimulation to ATM. A feed-forward paracrine inflammatory cycle involves co-cultured adipocytes release of FFA and macrophages FFA-induced TNF-a production, which blocks insulin-stimulated glucose uptake in adipocytes, and leads to increased release of FFA ${ }^{128}$. TNF- $a$ induces insulin resistance through several mechanisms including inhibition of insulin receptor signaling and increases in FFA ${ }^{129}$. M1 macrophages secrete a chemotactic proinflammatory lectin Galectin-3 that directly decreases insulin signaling and promotes adipose tissue inflammation ${ }^{130}$. Selective ablation of M1 macrophages $(\mathrm{CD} 11 \mathrm{c}+)$ by administration of diphtheria toxin in transgenic obese mice with expression of diphtheria toxin receptor under control of the CD11c promoter improved insulin sensitivity and lowered inflammatory markers ${ }^{131}$. Conversely, weight loss is associated with improved insulin sensitivity and induces a transient accumulation of M2 ATM driven by lipolysis in mice ${ }^{132}$.

We next review the mechanisms whereby the obesity-associated changes in ATM lead to inflammation and alter autophagy.

\subsection{Saturated fatty acids increase inflammatory ATM, activate the NLRP3 inflammasome, and decrease autophagy}

Obesity and the saturated fatty acid palmitate are associated with increased macrophage retention via increased netrin-1 expression in obese adipose tissue that promotes insulin resistance $^{133}$. Long chain saturated FFA but not unsaturated FFA induce an inflammatory response in macrophages that requires JNK signaling ${ }^{134}$.

The Nod-like receptor protein 3 (NLRP3) inflammasome detects the pore-forming exotoxins of Gram-positive bacteria but is also activated by a diversity of other stimuli. It initiates an inflammatory cascade that activates caspase- 1 and pyroptosis (proinflammatory programmed cell death) ${ }^{135}$. Activation of TLR4 by saturated fatty acids induces the NLRP3 inflammasome and IL-1 secretion by myeloid cells. 
Mitochondrial ROS are a trigger to NLRP3 activation ${ }^{136}$. Oxidized LDL also activates the NLRP3 inflammasome ${ }^{137}$. Coincubation of LPS and the saturated fatty acid palmitate, but not the unsaturated fatty acid oleate, induces activation of the NLRP3 inflammasome in bone marrow macrophages ${ }^{138}$.

Ceramides are composed of sphingosine and a fatty acid, and accumulate in obesity in response to saturated fatty acids and proinflammatory cytokines. Ceramides activate the NLRP3 inflammasome. Whole body and adipocyte-specific depletion of ceramides in mice by inhibiting their synthesis by serine palmitoyltransferase induces adipose tissue browning and increases M2 macrophages ${ }^{139}$. Ablation of NLRP3 in mice improves insulin sensitivity, reduces IL-18, and reduces effector T cells in adipose tissue ${ }^{140}$. Mice lacking TLR4 are protected from HFD-induced insulin resistance and inflammatory cytokine upregulation in adipocytes and hepatocytes ${ }^{141}$. Glyburide is a sulphonylurea used for the treatment of T2D which also inhibits the NLRP3 inflammasome and delays LPS induced lethality in mice ${ }^{142}$. Beta-hydroxybutyrate ${ }^{143}$ and the sulfonylurea MCC $950^{144}$ are inhibitors of NLRP3 and are promising therapeutic candidates for several NLRP3-mediated autoimmune diseases ${ }^{145}$.

Autophagy is an intracellular process responsible for degradation of proteins that has an anti-inflammatory effect. Loss of autophagic function through macrophage knockout of Atg5 increases M1 polarization, increases systemic and hepatic inflammation, but does not increase adipose tissue inflammation ${ }^{146}$. Loss of another autophagic protein Atg16L1 in macrophages increases LPS-induced production of pro-inflammatory IL- $1 \beta$ and IL-18 ${ }^{147}$. Mice fed SFA-rich HFD have decreased autophagy. Autophagic proteins inhibit the NLRP3 inflammasome by maintaining mitochondrial function and preserving mitochondrial integrity in macrophages ${ }^{148}$.

The GLP-1 agonist exendin-4 induced autophagy in monocytes from non-obese subjects which suppresses foam cell formulation but appear to have the opposite effects in monocytes from obese patients in a small study of 10 Japanese patients ${ }^{149}$. Further research is necessary as this does not seem consistent with the overall decrease in cardiovascular adverse outcomes seen in clinical trials of other GLP-1 agonists such as a large randomized controlled trial of liraglutide in 9340 patients ${ }^{150}$ and semaglutide in 3297 patients $^{151}$. Ongoing clinical trials are underway to determine whether this benefit is a class effect of GLP-1 agonists (NCT02465515, NCT01144338 and NCT01394952).

These results demonstrate that autophagy has important effects on macrophages, insulin sensitivity, and inflammation. The interactions between autophagy and metabolism have been reviewed in depth elsewhere ${ }^{152}$.

\subsection{Gut microbiota may also affect insulin sensitivity}

The inflammasomes may is also be involved in intestinal epithelial cells and maintenance of the gut microbiota. Obesity is associated with shifts in the gut microbiota. Host-gut microbiota interactions mediated by bile acids and LPS may affect macrophage polarization and host metabolism and immune responses ${ }^{153}$. For example, the gut microbe Akkermansia muciniphila has been recently shown to moderate the negative effects of IFN- $\gamma$ on glucose 
tolerance in mice and humans ${ }^{154}$. These interactions will require further comprehensive investigation in patients with inflammatory and metabolic diseases.

\subsection{Altered adipokine and cytokine secretion in obesity activates macrophages and inflammation}

Obesity is associated with altered immune systemic function through several mechanisms. Adipocyte size is an important determinant of adipokine secretion, and with obesity there is an increase in adipocyte size that correlates with increased secretion of macrophage inflammatory protein $1 \beta$, IL-1RA, CCL2 ${ }^{155}$. Obesity is associated adipocyte hypertrophy and with decreases in miRNAs in subcutaneous adipose tissue that attenuate CCL2 production $^{156}$.

Adipocytes release exosome-like vesicles that are taken up by monocytes where they promote differentiation into inflammatory macrophages and promote insulin resistance ${ }^{157}$. Retinol binding protein 4 (RBP4) is secreted by adipocytes and hepatocytes. RBP4 is increased in obese and insulin resistant subjects and induces proinflammatory cytokines (TNF-a, IL-6, CCL-2, IFN- $\gamma$, GM-CSF, IL-1, IL-2) through the JNK and TLR-4 pathways in macrophages ${ }^{158}$. Activation of the TLR4 signaling pathway requires mineralocorticoid receptors in bone marrow macrophages for phosphorylation of JNK and increased expression of downstream type 1 inflammatory markers ${ }^{159}$.

Male mice fed a HFD developed increased bone marrow cellularity and TNF-a production, and their bone marrow mesenchymal stem cells were primed towards adipogenesis ${ }^{160}$. ATM in visceral adipose tissue release cytokines such as IL- $1 \beta$ that increase bone marrow proliferation, resulting in monocytosis and neutrophilia ${ }^{161}$. Macrophages from DIO mice exhibit increased TNF- $a$ at baseline but reduced LPS stimulated release of TNF- $a$ after 4 hours or 24 hours ${ }^{162}$.

The CCL18 chemokine is produced by antigen presenting cells and macrophages in adipose tissue. CCL18 levels are higher in obese patients and positively correlated with ATP-III risk score, triglycerides, TNF- $a$, and IL- $6^{163}$.

Chemerin is a chemoattractant protein secreted by white adipose tissue whose receptor is expressed in macrophages and dendritic cells ${ }^{164}$. It recruits plasmacytoid dendritic cells into visceral adipose tissue, which upon activation secrete type I interferons that promote proinflammatory macrophage polarization ${ }^{165}$. Obese patients have increased chemerin, with associated inflammatory adipokine secretion and adipose tissue metabolic dysfunction ${ }^{166}$. Obese patients also have increased C-C chemokine receptor 7 (CCR7) expression in M1 ATM, which perpetuates chronic inflammation. Administration of a monoclonal antibody to CCR7 improved glucose tolerance in mice fed a HFD ${ }^{167}$. There are currently no registered clinical trials on anti-CCR7 therapies.

Adipose tissue macrophages secrete resistin, which activates TLR4 and has proinflammatory effects and induces monocyte migration via CCL2 ${ }^{168}$. Mice over-expressing CCL2 have increased insulin resistance on a HFD, whereas knockout mice exhibit reduced insulin resistance, hepatic steatosis, and adipose tissue macrophage infiltration on a HFD ${ }^{169}$. 
Resistin is largely produced by macrophages and monocytes in humans and is increased in obesity. Increases in resistin triggers hepatic lipogenesis and promotes vascular inflammation.

Compared with offspring of normal dams, male offspring of DIO mice have increased adipose CCL2 and TNF-a signaling accompanied by reduced miR-706 and increased inflammatory IL-33 and CAMK1D ${ }^{170}$. CCL2 is higher in obese subjects and is stimulated by IL-1, TNF- $\mathrm{a}$, IL-8, IL-4, and IL-6 and the IL-6-soluble receptor. In contrast, CCL2 is decreased by insulin, dexamethasone, IL-10, metformin, and thiazolidinediones ${ }^{171}$. In patients already taking simvastatin with impaired fasting glucose, metformin significantly reduced plasma FFA, CRP, and stimulated monocyte release of TNF-a, IL-1 $\beta$, IL-6, IL-8 and CCL2 ${ }^{172}$. Hence, the some of pleiotropic benefits of metformin may also be due to its inhibitory effect on inflammatory ATM secretion.

The vicious circle between hypertrophic adipocytes, lymphocytes, and M1 macrophages leads to ongoing activation of inflammatory cells and formation of CLS that induces further metabolic dysfunction. We next review the role of CLS in the progression towards diabetes and adipose tissue fibrosis.

\subsection{Crown-like structures are a hallmark of adipocyte dysfunction and are associated with disease progression}

CLS are composed of macrophages and T cells surrounding a single adipocyte and are associated with adipose tissue dysfunction and chronic inflammation. Adipocyte cell hypertrophy is associated with increased necrotic-like death that triggers macrophages to form CLS around them ${ }^{173}$. In humans with morbid obesity, there are twice as many macrophages in visceral (omental) adipose tissue compared with in subcutaneous adipose tissue. Increased CLS in omental adipose tissue is associated with worsening hepatic fibroinflammatory lesions, suggesting that CLS may contribute to progression of nonalcoholic fatty liver disease ${ }^{174}$.

Polycystic ovarian syndrome (PCOS) is a common endocrine disorder characterized by hyperandrogenism, menstrual irregularities, infertility, and hirsutism. It is also associated with obesity, metabolic syndrome, insulin resistance, and increased density of CLS in adipose tissue compared to BMI matched controls ${ }^{175}$. It has also recently been shown to be associated with increased IL-6, ICAM-1, ROS production, and ER stress ${ }^{176}$.

The semisynthetic bile acid obeticholic acid binds to the farsenoid $\mathrm{X}$ receptor, a nuclear receptor that regulates adipose function and macrophage polarization. Administration of obeticholic acid to mice on an atherogenic diet reduced CLS in periovarian and mesenteric adipose tissue and reduced CCR2 and CD11c mRNA expression ${ }^{177}$.

CLS in human subcutaneous and omental fat are predominantly composed of M1 macrophages, but also B and T lymphocytes. The B:T cell ratio within CLS is increased in patients with or without T2D who are on metformin ${ }^{178}$. 


\subsection{B cells, T cells, and NK cells propagate adipose tissue inflammation}

Obesity has been shown in mice to be associated with increased B cell production of TNF-a and macrophage inflammatory protein-2 (MIP-2), an ortholog of human IL-8, which leads to increased macrophage content in epididymal adipose tissue ${ }^{179}$. B cells in DIO mice recruit pro-inflammatory $\mathrm{T}$ cells and macrophages to adipose tissue, and secrete higher amounts of MIP-2, after stimulation with LPS ${ }^{180}$. These B cells also produce pathogenic IgG antibodies that induced glucose intolerance, inflammatory cytokine production, and M1 phenotype shift in visceral adipose tissue upon transfer to DIO B cell null mice on $\mathrm{HFD}^{181}$. Depletion of B cells with a CD20-targeting monoclonal antibody administered 6-7 weeks after HFD improved glucose metabolism. Compared to BMI matched controls, subjects with diabetes have increased Th17 cytokines that stimulate TNF-a production that can be decreased by B cell depletion ${ }^{182}$. Insulin resistant obese male humans have a unique profile of IgG autoantibodies compared with age- and weight-matched insulin sensitive males ${ }^{181}$.

Obesity is associated with activation of the innate immune system and infiltration of macrophages and $\mathrm{T}$ cells into metabolic tissues through alterations in cell recruitment, proliferation, and egress. CD8+ T cells recruit macrophages to adipose tissue in DIO mice ${ }^{183}$. CD40L is primarily expressed on activated T cells and binds to CD40 on macrophages, providing a potent activating signal. CD40 knockout mice and mice treated with an anti-CD40 neutralizing antibody are protected against obesity induced inflammation and insulin resistance ${ }^{184}$.

Compared to healthy controls, patients with obesity and T2D have reduced circulating mucosal associated invariant $\mathrm{T}$ cells, which are shifted towards an activated phenotype with elevated Th1 and Th17 cytokine production ${ }^{185}$. IL-17 levels were positively associated with the development of insulin resistance in the Cardiovascular Risk in Young Finns Study 186 and IL-17 levels correlated with hemoglobin A1c in patients with diabetes. Patients with T2D also have an altered $\mathrm{T}$ cell balance with increased Th17 and a reduced percent of Tregulatory cells ${ }^{187}$. Tregulatory cells maintain M2 macrophage polarization ${ }^{188}$. Obesity is also associated with increased adipose tissue NK cells that secrete TNF- $a$ and exacerbate HFD induced insulin resistance ${ }^{189}$.

Osteopontin is a Th1 cytokine secreted by M2 macrophages and T cells which functions as a chemoattractant to monocytes and preadipocytes. Osteopontin expression in adipose tissue is associated with macrophage infiltration and is decreased following bariatric surgery in humans ${ }^{190}$. At CLS, M2 macrophages express high levels of osteopontin. Knockout of osteopontin in mice prevented the formation of CLS and subsequent recruitment, proliferation, and differentiation of preadipocytes ${ }^{22}$. HFD-induced chronic inflammation in visceral fat with an accumulation of a distinct population of CD $153{ }^{+} \mathrm{PD}-1^{+} \mathrm{CD} 44^{\mathrm{hi}} \mathrm{CD} 4{ }^{+} \mathrm{T}$ cells. These $\mathrm{T}$ cells can induce insulin resistance upon transfer to lean mice and produce large amounts of osteopontin ${ }^{191}$. Osteopontin has also been implicated in the deposition of extracellular matrix and adipose tissue fibrosis, which are reviewed further in section 3.8.

Hence, it has been clearly demonstrated that both innate and adaptive immunity are involved in obesity-induced inflammation. Obesity is not only associated with an altered M1/M2 balance, but also an altered cytokine balance ${ }^{192}$ which may contribute to proinflammatory 
crosstalk between adipocytes, ATM, and B and T cells, propagation of inflammation, and CLS formation. We will now examine the consequences of inflammation-induced adipose tissue remodeling.

\subsection{Obesity is associated with adipose tissue inflammation and hypoxia}

Adipocyte hypertrophy leads to intracellular adipocyte stress, insulin resistance, and activation of proinflammatory pathways ${ }^{193}$. Chronic overnutrition-driven adipocyte hypertrophy leads to tissue growth that outpaces angiogenesis and a hypoxic microenvironment in obese humans ${ }^{194}$ and increased release of FFA ${ }^{195}$. Hypoxia activates hypoxia-inducible factor-1a, a transcription factor that activates inflammatory and fibrosis related genes, suppresses preadipocyte-related angiogenesis, and causes insulin resistance ${ }^{196}$. In contrast, smaller and more numerous subcutaneous adipocytes likely due to hyperplasia is associated with improved insulin sensitivity and HDL and decreased triglycerides in a study of Swedish bariatric surgery patients ${ }^{197}$.

The transition from lean to obese adipose tissue is marked by several changes in macrophage cytokine signaling and energy metabolism. This ultimately results in fibrotic dysfunctional adipose tissue, increased ectopic fat deposition, and insulin resistance ${ }^{198}$.

\subsection{Macrophage-driven adipose tissue inflammation and remodeling ultimately leads to fibrosis}

In addition to promoting insulin resistance and altering cytokines, inflammatory ATM may affect adipose tissue remodeling. Macrophage-secreted factors also increase pre-adipocyte gene expression of inflammatory cytokines IL-6 and IL-8. Treatment with an IL-1 $\beta$ neutralizing antibody reversed several of these changes in gene expression ${ }^{199}$. Adipocytes treated with a macrophage-conditioned medium containing macrophage-secreted factors have increased gene expression of 1,088 genes including endopeptidases called matrix metalloproteinases (MMP) that lead to fibrotic tissue remodeling 200 .

Tenascin C (TNC) is an extracellular protein induced by TGF- $\beta$ nearly absent in normal healthy adult tissues but over-expressed in human adipocytes following activation by macrophages. Macrophage-secreted factors increase expression of genes related to the extracellular matrix (TNC, a5-integrin, fibronectin, collagen I) that contribute to fibrosis. TNC is increased in the visceral adipose tissue of obese subjects, and DIO or genetically obese mice and is positively correlated with MMP9 and MM2, suggesting that it may be a mediator of obesity associated extracellular matrix remodeling ${ }^{201}$.

Adipose tissue from obese subjects has increased fibrosis, both M1 and M2 macrophages, and TGF- $\beta$ activity ${ }^{202}$. ATM secretion of TGF- $\beta$ induces a myofibroblast-like phenotype of adipose progenitor cells in humans ${ }^{20}$. Adipose hypertrophy leads to hypoxia, free fatty acid fluxes, and adipocyte death, which induce extensive tissue remodeling of the extracellular matrix and deposition of collagen $\mathrm{VI}^{203}$. Post-translational processing of collagen VI fibrils by MMP releases the adipokine endotrophin, which stimulates fibrosis and induces macrophage accumulation ${ }^{204}$. Fibrosis is stimulated by TGF- $\beta 1$ and by AMPK inhibition, which can be potentially prevented by treatment with metformin ${ }^{205}$. a-tocopherol is an antioxidant that decreased oxidative stress, improved insulin sensitivity, and reduced 
collagen deposition in the visceral adipose tissue of HF-diet fed mice ${ }^{206}$. Adiponectin inhibits NFKB signaling and upregulates AMPK and has potent anti-fibrotic effects on cultured fibroblasts ${ }^{207}$.

The extracellular matrix $(\mathrm{ECM})$ regulates adipocyte metabolism such that non-diabetic ECM that has been decellularized and then repopulated with adipocytes from patients with T2D partially rescues the defective glucose uptake and lipolysis ${ }^{208}$.

Obesity-induced matrix remodeling alters the microenvironment with consequences for cell migration, proliferation, differentiation, and function ${ }^{209}$. This remodeling is orchestrated by macrophages that regulate fibrogenesis by their secretion of MMP and their inhibitors leading to altered angiogenesis, recruitment of fibroblasts, ectopic fat deposition, insulin resistance and ultimately $\mathrm{T}_{2} \mathrm{D}^{210}$ (Figure 2). However, the data supporting this progression towards increasing fibrosis and insulin resistance are conflicting as a recent study in patients undergoing bariatric surgery found decreased fibrosis and preadipocytes in T2D patients compared with obese patients without $\mathrm{T} 2 \mathrm{D}^{211}$. These studies are potentially confounded by use of medications for T2D which have anti-fibrotic effects such as metformin and TZDs.

In the preceding sections we have discussed how obesity is associated with oxidative stress, macrophage activation, insulin resistance, and inflammation. CLS are sites of adipose tissue remodeling and form an adipogenic niche for preadipocytes leading to activation of $\mathrm{B}, \mathrm{T}$, and NK cells and ultimately tissue fibrosis. The relationships between these processes are summarized in Figure 3. We now review some of the therapeutic targets in these processes.

\section{Therapeutic implications of macrophage biology}

\subsection{Anti-inflammatory therapies for diabetes in development}

Patients with newly diagnosed T2D had 76\% higher serum LPS and 154\% higher TNF-a compared with matched controls with a similar $\mathrm{BMI}^{212}$. Diabetes skews the transcriptome of macrophages towards a pro-inflammatory state ${ }^{213}$. T2D is commonly associated with other chronic inflammatory conditions such as periodontitis. The inflammatory response of macrophages is regulated by bromodomain and extraterminal domain (BET) proteins that control gene transcription. BET inhibition by JQ1 rescues endotoxemic mice from lethal increases in IL-6 and TNF- $\mathrm{a}^{214}$. In a murine periodontitis model, JQ1 inhibits the TLR2/4$\mathrm{NF}-\kappa \mathrm{B}$ pathway in LPS-treated macrophages and significantly lowers inflammatory cytokines, which decreases alveolar bone $\operatorname{loss}^{215}$. Periodontitis induces chronic inflammation and endotoxinemia, which enhances macrophage activation, cholesterol uptake, and foam cell formation leading to atherogenesis ${ }^{216}$. Metabolic syndrome and T2D are associated with increased serum glucose, FFA, and insulin levels and accelerated atherosclerosis. Glucose, FFA, and insulin have been demonstrated to enhance conversion of macrophages to foam cell in vitro by increasing perilipin 3 expression ${ }^{217}$. RVX000222 is a BET inhibitor which has advanced to phase III clinical trial examining time to major cardiovascular events for patients with high risk T2D (NCT02586155). Hence, BET and perilipin 3 are potential therapeutic targets for T2D. 
Insulin-naïve patients with T2D developed an influx of macrophages into adipose tissue independent of weight gain 6 months after initiation of insulin therapy ${ }^{218}$. Lowering insulin levels in obese mice with streptozotocin or diazoxide decreased macrophage content in adipose tissue ${ }^{219}$. These results are counterintuitive since short-term studies of healthy human subjects infused with insulin found a decrease in CCL2, NFkB, ROS, and soluble ICAM-1 suggesting an anti-inflammatory effect ${ }^{220}$. Furthermore, insulin deficient mice with $\beta$-cell knockout of the cholesterol transporters ABCA1 and ABCG1 had increases in adiposity and ATM and reduced skeletal muscle mass. Insulin supplementation reversed the adipose tissue expansion in these mice but not the increased ATM or systemic inflammation ${ }^{221}$. Hence, insulin replacement in insulin deficient mice has beneficial properties but chronic hyperinsulinemia may have adverse metabolic consequences.

The various clinical trials of anti-inflammatory drugs for T2D have been reviewed elsewhere 222 so only a few representative examples are discussed here. The CCR2 antagonist CCX140-B in mice reduces adipose tissue macrophage content and improves insulin sensitivity 223,224 . Clinical trials of CCX140-B demonstrated improved fasting glucose and a modest decrease in hemoglobin A1c of $0.14 \%^{225}$. Anakinra is a monoclonal antibody to IL-1 $\beta$ (and possibly IL-1a) that induces improvement in the pro-insulin to insulin ratio, and reductions in CRP and IL-6 in patients with T2D ${ }^{226}$. Canakimumab inhibits IL- $1 \beta$ and lowered CRP, IL-6, fibrinogen, and hemoglobin A1c slightly 227 .

However, the use of anti-inflammatory therapies to alter adipose tissue function may be done cautiously as some degree of inflammation may be essential to normal physiology. For example, mice with impaired local pro-inflammatory potential responses in adipose tissue due to a dominant negative TNF- $a$ construct had increased ectopic lipid accumulation, increased intestinal permeability, and glucose intolerance with $\mathrm{HFD}^{228}$. Hence, adipose tissue inflammation is required for healthy adipose tissue expansion and filtering gut derived toxins. These intricate association between inflammation and metabolism need to be heeded in order for targeted anti-inflammatory therapies to be successful for the treatment of metabolic diseases.

\subsection{Diet and lifestyle modifications affect macrophages and inflammation}

The effects of diets on adipose tissue inflammation have been studied in both animal models and clinical trials. Animal models have elucidated many aspects of macrophage biology that may apply to human physiology but caution is needed due to biological differences between mouse models and humans ${ }^{6}$. While some molecular aspects are highly conserved across species, there are species differences and limitations to the findings from genetically manipulated animal models. With those caveats in mind, we now review the data on how exercise and dietary changes can affect adipose tissue inflammation.

Endurance exercise exerts global anti-inflammatory effects including skeletal muscle and adipose tissue and modulates polarization of ATM towards a M2 phenotype ${ }^{229}$. The antiinflammatory effects of exercise on systemic inflammation and ATM infiltration have been reviewed elsewhere ${ }^{230}$. Exercise is associated with increased IL-6, which promotes M2 polarization of macrophages ${ }^{231}$ and AMPK activation leading to increased fatty acid oxidation and decreased insulin resistance ${ }^{232}$. A twice-weekly aerobic exercise program for 
6 months in overweight patients with T2D was associated with significant decreases in Pselectin and ICAM-1 even in the absence of weight loss or reduced weight circumference $^{233}$.

The effects of dietary proteins, fats, and overall calorie content on inflammation have been recently extensively studied ${ }^{234}$. The type of dietary protein (plant vs. animal) in an 8-week hypo-caloric dietary trial in patients with metabolic syndrome affected markers of systemic inflammation including IL-6 and TNF- ${ }^{235}$. Similarly, a saturated fatty acid-rich diet compared with a mono-unsaturated fatty acid rich diet for eight weeks induced upregulation of inflammatory gene and chemokine expression in adipose tissue, although no differences in macrophage infiltration of adipose tissue was seen ${ }^{236}$. A high saturated fat highcarbohydrate meal compared with an isocaloric meal rich in fiber and fruit increased serum TLR4 protein expression in serum mononuclear cells and FFA and LPS levels ${ }^{237}$. The addition of orange juice to this meal prevented the meal-induced ROS generation by peripheral mononuclear cells and increase in MMP-9 mRNA and SOCS-3 protein consistent with an antioxidant and anti-inflammatory protective effect ${ }^{238}$. A subsequent study by this group showed that the addition of soluble fiber to a high-fat high-carbohydrate meal reduced hyperglycemia, reduced the rise in soluble DPP4, increased insulin, reduced LPS and oxidative and inflammatory stress following the meal ${ }^{239}$.

The macronutrient ratios may also influence inflammation and adipocyte function, since a hypocaloric high fat low carb diet produced similar reductions in body weight but lower CRP and higher total adiponectin compared with a hypocaloric low-fat high-carbohydrate diet $^{240}$. These effects may be mediated by FGF21 genotype as mentioned earlier although these were not measured in this study.

Omega-3 fatty acids stimulate $\mathrm{G}$ protein-coupled receptor 120 , which enhances glucose uptake in adipocytes. This also promotes M2 polarization in adipose tissue and decreases inflammatory macrophage infiltration in adipose tissue ${ }^{241}$. In mice, addition of eicosapentanoic acid to a high fat diet lowered gonadal adipose tissue CCL2 and PAI-1 levels ${ }^{242}$. Omega-3 fatty acid supplementation with 4 grams per day of fish oil in patients with metabolic syndrome decreased ATM and reduced CCL2 expression in subjects with insulin resistance ${ }^{243}$. Omega-3 feeding also increased levels of Resolvin D1, which was associated with decreased insulin resistance and ATM M1:M2 ratio, and increased adiponectin and AMPK phosphorylation ${ }^{244}$.

In addition to their macronutrient ratios, the overall caloric content and the duration of dietary interventions also affect adipose tissue inflammation. After 28 days of a very lowcalorie diet (VLCD), subcutaneous adipose tissue secretion of CCL2 and IL-6 from were significantly increased, consistent with increased adipose tissue inflammation ${ }^{245}$. A longer dietary intervention consisting of 1-month of VLCD followed by 2 months of low-calorie diet and then 3 months of weight-maintenance in 27 obese premenopausal women significantly decreased body weight and macrophage mRNA levels in adipose tissue along with plasma CCL2 levels without affecting macrophages polarization assessed by CD16 ${ }^{246}$. 
These studies demonstrate that interventions that increase energy expenditure through exercise, alter energy intake, or alter dietary nutrients, affect some of the pathways involved in adipose tissue inflammation. However, there are barriers to widespread adoption and maintenance of these lifestyle interventions. Bariatric surgery has been shown to lead to more sustained weight loss than lifestyle interventions. We now review the effects of bariatric surgery on adipose tissue inflammation.

\subsection{Bariatric surgery may promote beneficial alterations in ATM}

The effects of bariatric surgery on inflammation in adipose tissue are complex and have been recently reviewed ${ }^{247}$. A study of 92 non-obese subjects who underwent laparoscopic surgery for elective cholecystectomy or hiatal-hernia repair showed increased macrophage markers genes in subcutaneous adipose tissue but no difference in visceral adipose tissue in metabolically unhealthy compared with metabolic healthy subjects ${ }^{248}$. In a randomized trial of a lifestyle intervention or Roux-en-Y gastric bypass (RYGB) in sixteen patients with obesity and T2D, the loss of $7 \%$ of body weight was associated with an increase in adipose tissue inflammation in subcutaneous adipose tissue in both groups, suggesting that the reduction in adipose tissue inflammation is not the mechanism whereby RYGB exerts its anti-diabetes effect ${ }^{249}$. However, in that trial $7 \%$ weight loss was achieved within 13 days after RYGB while the lifestyle intervention group required 277 days hence the different duration of these two interventions may be confounding. Another study found that 3 months after gastric bypass, there was a shift towards M2 polarization of macrophages in subcutaneous adipose tissue with improved glucose homeostasis ${ }^{250}$.

IL-32 is a recently characterized cytokine that increases adipocyte expression of genes related to inflammation and extracellular matrix. Obesity is associated with increased IL-32 levels, and these are reduced following bariatric surgery 251 . This cytokine may represents a therapeutic target and warrants further study.

Despite the adverse metabolic consequences of visceral abdominal fat, the addition of omentectomy to RYGB did not improve insulin sensitivity or cardiovascular risk factors so omentectomy is not considered for obese patients ${ }^{252}$. Evidently, bariatric surgery may also be considered immunomodulatory metabolic surgery, given its associated changes in adipokines and adipose tissue inflammation ${ }^{253}$. Ongoing research into the mechanisms for bariatric surgery is looking into its effects on microflora and bile acids and may need to new therapies for metaflammation.

\section{Current challenges and future directions}

Considerable progress has been made over the past two decades in the field of immunometabolism but several challenges remain. There are limitations to animal studies. There are conflicting results in the literature on several questions, likely due to differences in study design, duration, tissue depots, definitions of diseases, and molecular methods used. Gene knockout studies are imperfect models for human polymorphisms. Diet-induced obesity in mice may not be well representative of human overnutrition, which often occurs more slowly over decades with intermittent periods of weight loss. Animal studies are often conducted in sterile environments so the effects of gut microflora are altered. Animal models 
have also differences in their $\mathrm{B}$ and $\mathrm{T}$ cell responses that may not be generalizable to humans.

Due to these limitations, knowledge gathered from animal models often does not translate to clinical therapies for patients. Even in humans, there are conflicting data and studies have important limitations. There may be key differences between the various saturated fats some may be more inflammatory than others. Likewise, there are likely differences between the unsaturated fats Dietary studies are often short term and do not obtain tissue biopsies so long term effects on adipose tissue are not known.

With those caveats, we now highlight some of the key unresolved questions:

- What are the long-term effects of bariatric surgery on adipose inflammation?

- Why have anti-inflammatory therapies not been more successful for T2D?

- $\quad$ Is fibrosis adaptive or maladaptive as a means to prevent hypertrophy and increase hyperplasia?

- If adipose tissue cytokines are a significant source of metabolic dysfunction, why does neither subcutaneous liposuction nor visceral omentectomy improve metabolism?

- What degree of inflammation is necessary for physiological adipose tissue function? Would suppressing it below this threshold level be deleterious?

Further investigation in this field may lead to new insights and therapies for inflammatory and metabolic disease. Metformin and lifestyle interventions are effective in preventing progressive metabolic dysfunction but are often insufficient. Immunometabolism may lead to the development of new therapies or the reuse of existing medications for new indications. For example, using anti-inflammatory medications for metabolic diseases (i.e. anti-TNF for T2D) and using metabolic therapies for the treatment of inflammatory diseases (i.e. pioglitazone for NAFLD ${ }^{254}$, metformin for HIV lipodystrophy) with enormous potential. Better therapies are needed to prevent the epidemic of obesity from increasing metabolic and cardiovascular disease globally.

\section{Conclusions}

Adipose tissue is a complex plastic endocrine and lymphoid organ with profound effects of inflammation and metabolism. Across all multicellular animals, immunity and metabolism are fundamental highly conserved systems with intricate crosstalk mediated by macrophages. Adipose tissue macrophages have many roles and are altered towards a proinflammatory profile with obesity. Obesity is associated with dynamic changes in resident macrophage population polarization and adipocyte function. The exact mechanisms behind obesity-induced inflammation are under investigation; current data suggests that overnutrition leads to adipocyte hypertrophy and hypoxia, which activates macrophage infiltration and formation of CLS. This causes inflammatory cytokine release and leads to further adipocyte dysfunction and insulin resistance and ultimately results in adipose tissue fibrosis. Exercise, cold exposure, and substitution of dietary saturated fatty acids for 
unsaturated fatty acids can reduce inflammatory macrophage polarization. Several interleukins and adipokines that have been identified are potential targets for therapies. Targeted anti-inflammatory therapies hold promise to halt the vicious circle of obesityinduced adipose tissue inflammation.

\section{Acknowledgments}

The authors would like to thank Barbara Nikolajczyk for her helpful feedback

Funding: This work was supported by NIH P30DK046200 and R01 DK108056.

Caroline M. Apovian has received grants from Eli Lilly, Amylin, Aspire Bariatrics, GI Dynamics, Pfizer, SanofiAventis, Orexigen, MetaProteomics, Takeda, the Dr. Robert C. and Veronica Atkins Foundation, MYOS

Corporation, the Vela Foundation, Gelesis, Energesis and Coherence Lab, and has participated on advisory boards for Amylin, Merck, Johnson and Johnson, Arena, Nutrisystem, Zafgen, Sanofi-Aventis, Orexigen, EnteroMedics, GI Dynamics, Scientific Intake, Gelesis and Novo Nordisk. Dr. Apovian has also participated on the Takeda Speakers Bureau for the medication Contrave and owns stock in Science-Smart LLC.

\section{Abbreviations}

AMPK AMP-activated protein kinase

ATM adipose tissue macrophages

CRP C-reactive protein

DIO diet-induced obesity

DPP-4 dipeptidyl peptidase-4

FFA free fatty acids

GLP-1 glucagon-like peptide-1

HFD high fat diet

IFN- $\boldsymbol{\gamma}$ interferon- $\boldsymbol{\gamma}$

IL interleukin

JNK c-Jun N-terminal kinase

LPS lipopolysaccharide

LDL low density lipoprotein

MMP matrix metalloproteinase

miRNA microRNA

NF $\mathbf{B}$ nuclear factor kappa-light-chain-enhancer of activated B cells

NLRP3 Nod-like receptor protein 3

NO nitric oxide 


$\begin{array}{ll}\text { OIR } & \text { obesity-related insulin resistance } \\ \text { PCOS } & \text { polycystic ovarian syndrome } \\ \text { PPAR } & \text { peroxisome proliferator activated receptor } \\ \text { ROS } & \text { reactive oxygen species } \\ \text { SFA } & \text { saturated fatty acid } \\ \text { TNC } & \text { tenactin C } \\ \text { TZD } & \text { thiazolidinedione } \\ \text { TGF } & \text { transforming growth factor } \\ \text { TNF-a } & \text { tumor necrosis factor-a } \\ \text { T2D } & \text { type } 2 \text { diabetes } \\ \text { VLCD } & \text { very low-calorie diet }\end{array}$

\section{References}

1. Scherer PE. The multifaceted roles of adipose tissue - Therapeutic targets for diabetes and beyond: The 2015 Banting lecture. Diabetes. 2016; 65(6):1452-61. [PubMed: 27222389]

2. Cao H, Gerhold K, Mayers JR, Wiest MM, Watkins SM, Hotamisligil GS. Identification of a Lipokine, a Lipid Hormone Linking Adipose Tissue to Systemic Metabolism. Cell. 2008; 134(6): 933-44. [PubMed: 18805087]

3. Zhang X, Zhang G, Zhang H, Karin M, Bai H, Cai D. Hypothalamic IKK $\beta / N F-\kappa B$ and ER Stress Link Overnutrition to Energy Imbalance and Obesity. Cell. 2008; 135(1):61-73. [PubMed: 18854155]

4. Gregor MF, Hotamisligil GS. Inflammatory mechanisms in obesity. Annu Rev Immunol. 2011; 29:415-45. [PubMed: 21219177]

5. Medzhitov R. Origin and physiological roles of inflammation. Nature. 2008; 454(7203):428-35. [PubMed: 18650913]

6. Nikolajczyk BS, Jagannathan-Bogdan M, Denis GV. The outliers become a stampede as immunometabolism reaches a tipping point. Immunol Rev. 2012; 249(1):253-75. [PubMed: 22889227]

7. Hill AA, Reid Bolus W, Hasty AH. A decade of progress in adipose tissue macrophage biology. Immunol Rev. 2014; 262(1):134-52. [PubMed: 25319332]

8. Morris DL, Singer K, Lumeng CN. Adipose tissue macrophages: phenotypic plasticity and diversity in lean and obese states. Curr Opin Clin Nutr Metab Care. 2011; 14(4):341-346. [PubMed: 21587064]

9. Mantovani A, Sica A, Sozzani S, Allavena P, Vecchi A, Locati M. The chemokine system in diverse forms of macrophage activation and polarization. Trends Immunol. 2004; 25(12):677-86. [PubMed: 15530839]

10. Mosser DM, Edwards JP. Exploring the full spectrum of macrophage activation. Nat Rev Immunol. 2008; 8(12):958-69. [PubMed: 19029990]

11. Weisberg SP, McCann D, Desai M, Rosenbaum M, Leibel RL, Ferrante AW. Obesity is associated with macrophage accumulation in adipose tissue. J Clin Invest. 2003; 112(12):1796-808. [PubMed: 14679176]

12. Odegaard JI, Chawla A. Alternative Macrophage Activation and Metabolism. Annu Rev Pathol Mech Dis. 2011; 6(1):275-97. 
13. Schipper HS, Prakken B, Kalkhoven E, Boes M. Adipose tissue-resident immune cells: Key players in immunometabolism. Trends Endocrinol Metab. 2012; 23(8):407-15. [PubMed: 22795937]

14. Charrière G, Cousin B, Arnaud E, et al. Preadipocyte Conversion to Macrophage: Evidence Of plasticity. J Biol Chem. 2003; 278(11):9850-5. [PubMed: 12519759]

15. Chazenbalk G, Bertolotto C, Heneidi S, et al. Novel pathway of adipogenesis through cross-talk between adipose tissue macrophages, adipose stem cells and adipocytes: Evidence of cell plasticity. PLoS One. 2011; 6(3)

16. Hubler MJ, Peterson KR, Hasty AH. Iron homeostasis: a new job for macrophages in adipose tissue? Trends Endocrinol Metab. 2015; 26(2):101-9. [PubMed: 25600948]

17. Morris DL, Cho KW, DelProposto JL, et al. Adipose Tissue Macrophages Function As AntigenPresenting Cells and Regulate Adipose Tissue CD4+ T Cells in Mice. Diabetes. 2013; 62(8):276272. [PubMed: 23493569]

18. Chen Y, Liu W, Sun T, et al. 1,25-Dihydroxyvitamin D Promotes Negative Feedback Regulation of TLR Signaling via Targeting MicroRNA-155-SOCS1 in Macrophages. J Immunol. 2013; 190(7): 3687-95. [PubMed: 23436936]

19. Ramon S, Dalli J, Sanger JM, et al. The Protectin PCTR1 Is Produced by Human M2 Macrophages and Enhances Resolution of Infectious Inflammation. Am J Pathol. 2016; 186(4):962-73. [PubMed: 26878209]

20. Bourlier V, Sengenès C, Zakaroff-Girard A, et al. TGF $\beta$ Family Members Are Key Mediators in the Induction of Myofibroblast Phenotype of Human Adipose Tissue Progenitor Cells by Macrophages. PLoS One. 2012; 7(2):e31274. [PubMed: 22355352]

21. Nishimura S, Manabe I, Nagasaki M, et al. Adipogenesis in Obesity Requires Close Interplay Between Differentiating Adipocytes, Stromal Cells, and Blood Vessels. Diabetes. 2007; 56(6): 1517-26. [PubMed: 17389330]

22. Lee Y-H, Petkova AP, Granneman JG. Identification of an Adipogenic Niche for Adipose Tissue Remodeling and Restoration. Cell Metab. 2016; 18(3):355-67.

23. Pang C, Gao Z, Yin J, Zhang J, Jia W, Ye J. Macrophage infiltration into adipose tissue may promote angiogenesis for adipose tissue remodeling in obesity. Am J Physiol - Endocrinol Metab. 2008; 295(2):E313-22. [PubMed: 18492768]

24. Sorisky A, Molgat ASD, Gagnon A. Macrophage-Induced Adipose Tissue Dysfunction and the Preadipocyte: Should I Stay (and Differentiate) or Should I Go? Adv Nutr An Int Rev J. 2013; 4(1):67-75.

25. Bouhlel MA, Derudas B, Rigamonti E, et al. PPAR $\gamma$ Activation Primes Human Monocytes into Alternative M2 Macrophages with Anti-inflammatory Properties. Cell Metab. 2007; 6(2):137-43. [PubMed: 17681149]

26. Osborn O, Olefsky JM. The cellular and signaling networks linking the immune system and metabolism in disease. Nat Med. 2012; 18(3):363-74. [PubMed: 22395709]

27. Odegaard JI, Ricardo-Gonzalez RR, Goforth MH, et al. Macrophage-specific PPAR $\gamma$ controls alternative activation and improves insulin resistance. Nature. 2007; 447(7148):1116-20. [PubMed: 17515919]

28. Patsouris D, Neels JG, Fan WQ, Li PP, Nguyen MTA, Olefsky JM. Glucocorticoids and thiazolidinediones interfere with adipocyte-mediated macrophage chemotaxis and recruitment. $\mathbf{J}$ Biol Chem. 2009; 284(45):31223-35. [PubMed: 19740750]

29. Koppaka S, Kehlenbrink S, Carey M, et al. Reduced adipose tissue macrophage content is associated with improved insulin sensitivity in thiazolidinedione-treated diabetic humans. Diabetes. 2013; 62(6):1843-54. [PubMed: 23349486]

30. Bodles AM, Varma V, Yao-Borengasser A, et al. Pioglitazone induces apoptosis of macrophages in human adipose tissue. J Lipid Res. 2006; 47(9):2080-8. [PubMed: 16799131]

31. Fu Y, Luo N, Lopes-Virella MF. Oxidized LDL induces the expression of ALBP/aP2 mRNA and protein in human THP-1 macrophages. J Lipid Res. 2000; 41(12):2017-23. [PubMed: 11108735]

32. Boord JB, Maeda K, Makowski L, et al. Adipocyte Fatty Acid-Binding Protein, aP2, Alters Late Atherosclerotic Lesion Formation in Severe Hypercholesterolemia. Arterioscler Thromb Vasc Biol. 2002; 22(10):1686-1691. [PubMed: 12377750] 
33. Makowski L, Boord JB, Maeda K, et al. Lack of macrophage fatty-acid-binding protein aP2 protects mice deficient in apolipoprotein E against atherosclerosis. Nat Med. 2001; 7(6):699-705. [PubMed: 11385507]

34. Hotamisligil GS, Johnson RS, Distel RJ, Ellis R, Papaioannou VE, Spiegelman BM. Uncoupling of Obesity from Insulin Resistance Through a Targeted Mutation in aP2, the Adipocyte Fatty Acid Binding Protein. Science. 1996; 274(5291):1377-79. [PubMed: 8910278]

35. Maeda K, Cao H, Kono K, et al. Adipocyte/macrophage fatty acid binding proteins control integrated metabolic responses in obesity and diabetes. Cell Metab. 2016; 1(2):107-19.

36. Odegaard JI, Ricardo-Gonzalez RR, Red Eagle A, et al. Alternative M2 Activation of Kupffer Cells by PPAR $\delta$ Ameliorates Obesity-Induced Insulin Resistance. Cell Metab. 2008; 7(6):496-507. [PubMed: 18522831]

37. Mukundan L, Odegaard JI, Morel CR, et al. PPAR- $\delta$ senses and orchestrates clearance of apoptotic cells to promote tolerance. Nat Med. 2009; 15(11):1266-72. [PubMed: 19838202]

38. Naya N, Fukao K, Nakamura A, et al. A selective peroxisome proliferator-activated receptor- $\delta$ agonist PYPEP suppresses atherosclerosis in association with improvement of the serum lipoprotein profiles in human apolipoprotein B100 and cholesteryl ester transfer protein double transgenic mice. Metab - Clin Exp. 2017; 65(1):16-25.

39. Elias I, Ferré T, Vilà L, et al. ALOX5AP overexpression in adipose tissue leads to LXA4 production and protection against diet-induced obesity and insulin resistance. Diabetes. 2016; 65(8):2139-50. [PubMed: 27207555]

40. Sha Y-H, Hu Y-W, Gao J-J, et al. Lipoxin A4 promotes ABCA1 expression and cholesterol efflux through the LXRa signaling pathway in THP-1 macrophage-derived foam cells. Int J Clin Exp Pathol. 2015; 8(6):6708-15. [PubMed: 26261553]

41. Virtue S, Masoodi M, de Weijer BAM, et al. Prostaglandin profiling reveals a role for haematopoietic prostaglandin D synthase in adipose tissue macrophage polarisation in mice and humans. Int J Obes. 2015; 39(7):1151-60.

42. Yore MM, Syed I, Moraes-Vieira PM, et al. Discovery of a class of endogenous mammalian lipids with anti-diabetic and anti-inflammatory effects. Cell. 2014; 159(2):318-32. [PubMed: 25303528]

43. Moraes-Vieira PM, Saghatelian A, Kahn BB. GLUT4 expression in adipocytes regulates de novo lipogenesis and levels of a novel class of lipids with antidiabetic and anti-inflammatory effects. Diabetes. 2016; 65(7):1808-15. [PubMed: 27288004]

44. Kuda O, Brezinova M, Rombaldova M, et al. Docosahexaenoic acid-derived fatty acid esters of hydroxy fatty acids (FAHFAS) with anti-inflammatory properties. Diabetes. 2016; 65(9):2580-90. [PubMed: 27313314]

45. Wu J, Boström P, Sparks LM, et al. Beige Adipocytes are a Distinct Type of Thermogenic Fat Cell in Mouse and Human. Cell. 2012; 150(2):366-76. [PubMed: 22796012]

46. Qiu Y, Nguyen KD, Odegaard JI, et al. Eosinophils and Type 2 Cytokine Signaling in Macrophages Orchestrate Development of Functional Beige Fat. Cell. 2016; 157(6):1292-308.

47. Wu D, Molofsky AB, Liang H-E, et al. Eosinophils Sustain Adipose Alternatively Activated Macrophages Associated with Glucose Homeostasis. Science. 2011; 332(6026):243-47. [PubMed: 21436399]

48. Nguyen KD, Qiu Y, Cui X, et al. Alternatively activated macrophages produce catecholamines to sustain adaptive thermogenesis. Nature. 2011; 480(7375):104-8. [PubMed: 22101429]

49. Rao RR, Long JZ, White JP, et al. Meteorin-like is a hormone that regulates immune-adipose interactions to increase beige fat thermogenesis. Cell. 2014; 157(6):1279-91. [PubMed: 24906147]

50. Li Z-Y, Song J, Zheng S-L, et al. Adipocyte Metrnl Antagonizes Insulin Resistance Through PPAR $\gamma$ Signaling. Diabetes. 2015; 64(12):4011-22. [PubMed: 26307585]

51. Zheng S, Li Z, Song J, Liu J, Miao C. Metrnl: a secreted protein with new emerging functions. Acta Pharmacol Sin. 2016; 37(5):571-9. [PubMed: 27063217]

52. Ohashi K, Parker JL, Ouchi N, et al. Adiponectin Promotes Macrophage Polarization toward an Anti-inflammatory Phenotype. J Biol Chem. 2010; 285(9):6153-60. [PubMed: 20028977]

53. Hui X, Gu P, Zhang J, et al. Adiponectin Enhances Cold-Induced Browning of Subcutaneous Adipose Tissue via Promoting M2 Macrophage Proliferation. Cell Metab. 2016; 22(2):279-90. 
54. Hussaarts L, García-Tardón N, van Beek L, et al. Chronic helminth infection and helminth-derived egg antigens promote adipose tissue M2 macrophages and improve insulin sensitivity in obese mice. FASEB J. 2015; 29(7):3027-39. [PubMed: 25852044]

55. Li Y, Goto T, Ikutani R, et al. Xanthoangelol and 4-hydroxyderrcin suppress obesity-induced inflammatory responses. Obesity. 2016; 24(11):2351-60. [PubMed: 27619735]

56. Rossi F, Bellini G, Luongo L, et al. Cannabinoid Receptor 2 as Antiobesity Target: Inflammation, Fat Storage, and Browning Modulation. J Clin Endocrinol Metab. 2016; 101(9):3469-78. [PubMed: 27294325]

57. Giordano A, Frontini A, Cinti S. Convertible visceral fat as a therapeutic target to curb obesity. Nat Rev Drug Discov. 2016; 15(6):405-24. [PubMed: 26965204]

58. van den Berg SM, van Dam AD, Rensen PCN, de Winther MPJ, Lutgens E. Immune Modulation of Brown(ing) Adipose Tissue in Obesity. Endocr Rev. 2017; 38(1):46-68. [PubMed: 27849358]

59. Sarvari AK, Doan-Xuan Q-M, Bacso Z, Csomos I, Balajthy Z, Fesus L. Interaction of differentiated human adipocytes with macrophages leads to trogocytosis and selective IL-6 secretion. Cell Death Dis. 2015; 6:e1613. [PubMed: 25611388]

60. Ye J, McGuinness OP. Inflammation during obesity is not all bad: evidence from animal and human studies. Am J Physiol -Endocrinol Metab. 2013; 304(5):E466-477. [PubMed: 23269411]

61. Tang T, Zhang J, Yin J, et al. Uncoupling of Inflammation and Insulin Resistance by NF- $\mathrm{B}$ in Transgenic Mice through Elevated Energy Expenditure. J Biol Chem. 2010; 285(7):4637-4644. [PubMed: 20018865]

62. Fried SK, Zechner R. Cachectin/tumor necrosis factor decreases human adipose tissue lipoprotein lipase mRNA levels, synthesis, and activity. J Lipid Res. 1989; 30(12):1917-23. [PubMed: 2695592]

63. Marra M, Campanati A, Testa R, et al. Effect of etanercept on insulin sensitivity in nine patients with psoriasis. Int J Immunopathol Pharmacol. 2007; 20:731-6. [PubMed: 18179745]

64. Kofoed K, Clemmensen A, UR M, Simonsen L, Andersen O, Gniadecki R. EFfects of anti-tumor necrosis factor therapy on body composition and insulin sensitivity in patients with psoriasis. Arch Dermatol. 2012; 148(9):1089-91. [PubMed: 22986877]

65. Dominguez H, Storgaard H, Rask-Madsen C, et al. Metabolic and vascular effects of tumor necrosis factor-a blockade with etanercept in obese patients with type 2 diabetes. J Vasc Res. 2005; 42(6):517-25. [PubMed: 16155368]

66. Renzo LD, Saraceno R, Schipani C, et al. Prospective assessment of body weight and body composition changes in patients with psoriasis receiving anti- TNF- treatment. Dermatol Ther. 2011; 24(4):446-451. [PubMed: 21910803]

67. Lavery CA, Kurowska-Stolarska M, Holmes WM, et al. miR-34a(-/-) mice are susceptible to dietinduced obesity. Obesity (Silver Spring). 2016; 24(8):1741-51. [PubMed: 27377585]

68. Fu T, Seok S, Choi S, et al. MicroRNA 34a Inhibits Beige and Brown Fat Formation in Obesity in Part by Suppressing Adipocyte Fibroblast Growth Factor 21 Signaling and SIRT1 Function. Mol Cell Biol. 2014; 34(22):4130-42. [PubMed: 25182532]

69. Heianza Y, Ma W, Huang T, et al. Macronutrient Intake-Associated FGF21 Genotype Modifies Effects of Weight-Loss Diets on 2-Year Changes of Central Adiposity and Body Composition: The POUNDS Lost Trial. Diabetes Care. 2016; 39(11):1909-14. [PubMed: 27581055]

70. Yu Y, He J, Li S, et al. Fibroblast growth factor 21 (FGF21) inhibits macrophage-mediated inflammation by activating Nrf2 and suppressing the NF- $\mathrm{kB}$ signaling pathway. Int Immunopharmacol. 2016; 38:144-52. [PubMed: 27276443]

71. Kemmerer M, Finkernagel F, Cavalcante MF, et al. AMP-Activated Protein Kinase Interacts with the Peroxisome Proliferator-Activated Receptor Delta to Induce Genes Affecting Fatty Acid Oxidation in Human Macrophages. PLoS ONE. 2015; 10(6):e0130893. [PubMed: 26098914]

72. Sag D, Carling D, Stout RD, Suttles J. Adenosine 5'-Monophosphate-Activated Protein Kinase Promotes Macrophage Polarization to an Anti-Inflammatory Functional Phenotype. J Immunol. 2008; 181(12):8633-41. [PubMed: 19050283]

73. Yang Z, Kahn BB, Shi H, Xue B. Macrophage a 1 AMP-activated Protein Kinase (a1AMPK) Antagonizes Fatty Acid-induced Inflammation through SIRT1. J Biol Chem. 2010; 285(25): 19051-9. [PubMed: 20421294] 
74. Galic S, Fullerton MD, Schertzer JD, et al. Hematopoietic AMPK $\beta 1$ reduces mouse adipose tissue macrophage inflammation and insulin resistance in obesity. J Clin Invest. 121(12):4903-15.

75. Liang Y, Yuan W, Zhu W, et al. Macrophage migration inhibitory factor promotes expression of GLUT4 glucose transporter through MEF2 and Zac1 in cardiomyocytes. Metabolism. 2015; 64(12):1682-93. [PubMed: 26455966]

76. Ruderman NB, Keller C, Richard A-M, et al. Interleukin-6 Regulation of AMP-Activated Protein Kinase. Diabetes. 2006; 55(Supplement 2):S48-54. [PubMed: 17130644]

77. Scheller J, Chalaris A, Schmidt-Arras D, Rose-John S. The pro- and anti-inflammatory properties of the cytokine interleukin-6. Biochim Biophys Acta - Mol Cell Res. 2011; 1813(5):878-88.

78. Ruderman NB, Carling D, Prentki M, Cacicedo JM. AMPK, insulin resistance, and the metabolic syndrome. J Clin Invest. 2013; 123(7):2764-72. [PubMed: 23863634]

79. Weikel KA, Ruderman NB, Cacicedo JM. Unraveling the actions of AMP-activated protein kinase in metabolic diseases: Systemic to molecular insights. Metabolism. 2016; 65(5):634-45. [PubMed: 27085772]

80. Vasamsetti SB, Karnewar S, Kanugula AK, Thatipalli AR, Kumar JM, Kotamraju S. Metformin Inhibits Monocyte-to-Macrophage Differentiation via AMPK-Mediated Inhibition of STAT3 Activation: Potential Role in Atherosclerosis. Diabetes. 2015; 64(6):2028-41. [PubMed: 25552600]

81. Kim J, Yang G, Kim Y, Kim J, Ha J. AMPK activators: mechanisms of action and physiological activities. Exp Mol Med. 2016; 48:e224. [PubMed: 27034026]

82. Singer K, Morris DL, Oatmen KE, et al. Neuropeptide Y Is Produced by Adipose Tissue Macrophages and Regulates Obesity-Induced Inflammation. PLoS One. 2013; 8(3):e57929. [PubMed: 23472120]

83. Aronis KN, Tsoukas MA, Mantzoros CS. Potential cardioprotective action of GLP-1: from bench to bedside. Metab - Clin Exp. 2017; 63(8):979-88.

84. Lee D-S, Lee E-S, Alam MM, et al. Soluble DPP-4 up-regulates toll-like receptors and augments inflammatory reactions, which are ameliorated by vildagliptin or mannose-6-phosphate. Metab Clin Exp. 2017; 65(2):89-101.

85. Zhuge F, Ni Y, Nagashimada M, et al. DPP-4 Inhibition by Linagliptin Attenuates Obesity-Related Inflammation and Insulin Resistance by Regulating M1/M2 Macrophage Polarization. Diabetes. 2016; 65(10):2966-79. [PubMed: 27445264]

86. Hirano T, Yamashita S, Takahashi M, Hashimoto H, Mori Y, Goto M. Anagliptin, a dipeptidyl peptidase-4 inhibitor, decreases macrophage infiltration and suppresses atherosclerosis in aortic and coronary arteries in cholesterol-fed rabbits. Metab - Clin Exp. 2017; 65(6):893-903.

87. Satoh-Asahara N, Sasaki Y, Wada H, et al. A dipeptidyl peptidase-4 inhibitor, sitagliptin, exerts anti-inflammatory effects in type 2 diabetic patients. Metab - Clin Exp. 2017; 62(3):347-51.

88. Green JB, Bethel MA, Armstrong PW, et al. Effect of Sitagliptin on Cardiovascular Outcomes in Type 2 Diabetes. N Engl J Med. 2015; 373(3):232-42. [PubMed: 26052984]

89. Michaud A, Drolet R, Noël S, Paris G, Tchernof A. Visceral fat accumulation is an indicator of adipose tissue macrophage infiltration in women. Metab - Clin Exp. 2017; 61(5):689-98.

90. Lumeng CN, Bodzin JL, Saltiel AR. Obesity induces a phenotypic switch in adipose tissue macrophage polarization. J Clin Invest. 2007; 117(1):175-84. [PubMed: 17200717]

91. Stefanovic-Racic M, Yang X, Turner MS, et al. Dendritic Cells Promote Macrophage Infiltration and Comprise a Substantial Proportion of Obesity-Associated Increases in CD11c(+) Cells in Adipose Tissue and Liver. Diabetes. 2012; 61(9):2330-9. [PubMed: 22851575]

92. Wensveen FM, Valentić S, Šestan M, Turk Wensveen T, Polić B. The "Big Bang" in obese fat: Events initiating obesity-induced adipose tissue inflammation. Eur J Immunol. 2015; 45(9):244656. [PubMed: 26220361]

93. Boutens L, Stienstra R. Adipose tissue macrophages: going off track during obesity. Diabetologia. 2016; 59(5):879-94. [PubMed: 26940592]

94. Lumeng CN, Liu J, Geletka L, et al. Aging Is Associated with an Increase in T Cells and Inflammatory Macrophages in Visceral Adipose Tissue. J Immunol. 2011; 187(12):6208-16. [PubMed: 22075699] 
95. Bosanska L, Michalsky D, Lacinova Z, et al. The influence of obesity and different fat depots on adipose tissue gene expression and protein levels of cell adhesion molecules. Physiol Res. 2010; 59(1):79-88. [PubMed: 19249917]

96. Chow FY, Nikolic-Paterson DJ, Ozols E, Atkins RC, Tesch GH. Intercellular Adhesion Molecule-1 Deficiency Is Protective against Nephropathy in Type 2 Diabetic db/db Mice. J Am Soc Nephrol. 2005; 16(6):1711-22. [PubMed: 15857924]

97. Jang JE, Ko MS, Yun J-Y, et al. Nitric Oxide Produced by Macrophages Inhibits Adipocyte Differentiation and Promotes Profibrogenic Responses in Preadipocytes to Induce Adipose Tissue Fibrosis. Diabetes. 2016; 65(9):2516-28. [PubMed: 27246913]

98. Van den Bossche J, Baardman J, Otto NA, et al. Mitochondrial Dysfunction Prevents Repolarization of Inflammatory Macrophages. Cell Rep. 2016; 17(3):684-96. [PubMed: 27732846]

99. Boden G, Homko C, Barrero CA, et al. Excessive caloric intake acutely causes oxidative stress, GLUT4 carbonylation, and insulin resistance in healthy men. Sci Transl Med. 2015; 7(304):1-9.

100. Furukawa S, Fujita T, Shimabukuro M, et al. Increased oxidative stress in obesity and its impact on metabolic syndrome. J Clin Invest. 2004; 114(12):1752-61. [PubMed: 15599400]

101. Ham M, Choe SS, Shin KC, et al. Glucose-6-phosphate dehydrogenase deficiency improves insulin resistance with reduced adipose tissue inflammation in obesity. Diabetes. 2016; 65:262438. [PubMed: 27284106]

102. Park J, Choe SS, Choi AH, et al. Increase in Glucose-6-Phosphate Dehydrogenase in Adipocytes Stimulates Oxidative Stress and Inflammatory Signals. Diabetes. 2006; 55(11):2939-49. [PubMed: 17065329]

103. Baldwin W, McRae S, Marek G, et al. Hyperuricemia as a Mediator of the Proinflammatory Endocrine Imbalance in the Adipose Tissue in a Murine Model of the Metabolic Syndrome. Diabetes. 2011; 60(4):1258-69. [PubMed: 21346177]

104. Li P, Oh DY, Bandyopadhyay G, et al. LTB4 promotes insulin resistance in obese mice by acting on macrophages, hepatocytes and myocytes. Nat Med. 2015; 21(3):239-47. [PubMed: 25706874]

105. Spite M, Hellmann J, Tang Y, et al. Deficiency of the Leukotriene B4 Receptor, BLT-1, Protects against Systemic Insulin Resistance in Diet-Induced Obesity. J Immunol. 2011; 187(4):1942-9. [PubMed: 21742977]

106. Devchand PR, Keller H, Peters JM, Vazquez M, Gonzalez FJ, Wahli W. The PPAR[alpha]leukotriene B4 pathway to inflammation control. Nature. 1996; 384(6604):39-43. [PubMed: 8900274]

107. Poynter ME, Daynes RA. Peroxisome Proliferator-activated Receptor a Activation Modulates Cellular Redox Status, Represses Nuclear Factor- $\kappa$ B Signaling, and Reduces Inflammatory Cytokine Production in Aging. J Biol Chem. 1998; 273(49):32833-41. [PubMed: 9830030]

108. Esteghamati A, Eskandari D, Mirmiranpour H, et al. Effects of metformin on markers of oxidative stress and antioxidant reserve in patients with newly diagnosed type 2 diabetes: A randomized clinical trial. Clin Nutr. 2013; 32(2):179-85. [PubMed: 22963881]

109. Madiraju AK, Erion DM, Rahimi Y, et al. Metformin suppresses gluconeogenesis by inhibiting mitochondrial glycerophosphate dehydrogenase. Nature. 2014; 510(7506):542-6. [PubMed: 24847880]

110. Okauchi Y, Kishida K, Funahashi T, et al. Cross-sectional and longitudinal study of association between circulating thiobarbituric acid-reacting substance levels and clinicobiochemical parameters in 1,178 middle-aged Japanese men - the Amagasaki Visceral Fat Study. Nutr Metab (Lond). 2011; 8:82. [PubMed: 22108213]

111. Nakatsuji H, Kishida K, Sekimoto R, et al. Accumulation of adiponectin in inflamed adipose tissues of obese mice. Metab -Clin Exp. 2017; 63(4):542-53.

112. Ma Z-G, Yuan Y-P, Xu S-C, et al. CTRP3 attenuates cardiac dysfunction, inflammation, oxidative stress and cell death in diabetic cardiomyopathy in rats. Diabetologia. 2017:1-12. [PubMed: 27858142]

113. Peterson JM, Wei Z, Wong GW. C1q/TNF-related Protein-3 (CTRP3), a Novel Adipokine That Regulates Hepatic Glucose Output. J Biol Chem. 2010; 285(51):39691-701. [PubMed: 20952387] 
114. Wolf RM, Steele KE, Peterson LA, Magnuson TH, Schweitzer MA, Wong GW. Lower Circulating C1q/TNF-Related Protein-3 (CTRP3) Levels Are Associated with Obesity: A CrossSectional Study. PLoS One. 2015; 10(7):e0133955. [PubMed: 26222183]

115. Han X, Tai H, Wang X, et al. AMPK activation protects cells from oxidative stress-induced senescence via autophagic flux restoration and intracellular NAD+ elevation. Aging Cell. 2016; 15(3):416-27. [PubMed: 26890602]

116. Xie L, Gu Y, Wen M, et al. Hydrogen sulfide induces keap1 S-sulfhydration and suppresses diabetes-accelerated atherosclerosis via Nrf2 activation. Diabetes. 2016; 65(10):3171-84. [PubMed: 27335232]

117. Whiteman M, Gooding KM, Whatmore JL, et al. Adiposity is a major determinant of plasma levels of the novel vasodilator hydrogen sulphide. Diabetologia. 2010; 53(8):1722-6. [PubMed: 20414636]

118. Chawla A, Nguyen KD, Goh YPS. Macrophage-mediated inflammation in metabolic disease. Nat Rev Immunol. 2011; 11(11):738-49. [PubMed: 21984069]

119. Grant RW, Boudreaux JI, Stephens JM. 2-deoxyglucose inhibits induction of chemokine expression in 3T3-L1 adipocytes and adipose tissue explants. Obesity. 2017; 25(1):76-84. [PubMed: 27706923]

120. Lo JC, Ljubicic S, Leibiger B, et al. Adipsin Is an Adipokine that Improves $\beta$ Cell Function in Diabetes. Cell. 2016; 158(1):41-53.

121. Mamane Y, Chung Chan C, Lavallee G, et al. The C3a Anaphylatoxin Receptor Is a Key Mediator of Insulin Resistance and Functions by Modulating Adipose Tissue Macrophage Infiltration and Activation. Diabetes. 2009; 58(9):2006-17. [PubMed: 19581423]

122. Maffei M, Barone I, Scabia G, Santini F. The Multifaceted Haptoglobin in the Context of Adipose Tissue and Metabolism. Endocr Rev. 2016; 37(4):403-16. [PubMed: 27337111]

123. Bueno AA, Oyama LM, de Macedo Motoyama CS, et al. Long chain saturated fatty acids increase haptoglobin gene expression in C57BL/6J mice adipose tissue and 3T3-L1 cells. Eur J Nutr. 2010; 49(4):235-41. [PubMed: 19856197]

124. Xu H, Barnes GT, Yang Q, et al. Chronic inflammation in fat plays a crucial role in the development of obesity-related insulin resistance. J Clin Invest. 112(12):1821-30.

125. Li P, Lu M, Nguyen MTA, et al. Functional Heterogeneity of CD11c-positive Adipose Tissue Macrophages in Diet-induced Obese Mice. J Biol Chem. 2010; 285(20):15333-45. [PubMed: 20308074]

126. Tam CS, Viardot A, Clément K, et al. Short-Term Overfeeding May Induce Peripheral Insulin Resistance Without Altering Subcutaneous Adipose Tissue Macrophages in Humans. Diabetes. 2010; 59(9):2164-70. [PubMed: 20547978]

127. Apovian CM, Bigornia S, Mott M, et al. Adipose Macrophage Infiltration Is Associated With Insulin Resistance and Vascular Endothelial Dysfunction in Obese Subjects. Arterioscler Thromb Vasc Biol. 2008; 28(9):1654-59. [PubMed: 18566296]

128. Suganami T, Nishida J, Ogawa Y. A Paracrine Loop Between Adipocytes and Macrophages Aggravates Inflammatory Changes. Arterioscler Thromb Vasc Biol. 2005; 25(10):2062-68. [PubMed: 16123319]

129. Uysal KT, Wiesbrock SM, Marino MW, Hotamisligil GS. Protection from obesity-induced insulin resistance in mice lacking TNF-[alpha] function. Nature. 1997; 389(6651):610-4. [PubMed: 9335502]

130. Li P, Liu S, Lu M, et al. Hematopoietic-Derived Galectin-3 Causes Cellular and Systemic Insulin Resistance. Cell. 2016; 167(4):973-84. [PubMed: 27814523]

131. Patsouris D, Li P-P, Thapar D, Chapman J, Olefsky JM, Neels JG. Ablation of CD11c-Positive Cells Normalizes Insulin Sensitivity in Obese Insulin Resistant Animals. Cell Metab. 2008; 8(4): 301-9. [PubMed: 18840360]

132. Kosteli A, Sugaru E, Haemmerle G, et al. Weight loss and lipolysis promote a dynamic immune response in murine adipose tissue. J Clin Invest. 120(10):3466-79.

133. Ramkhelawon B, Hennessy EJ, Ménager M, et al. Netrin-1 promotes adipose tissue macrophage retention and insulin resistance in obesity. Nat Med. 2014; 20(4):377-84. [PubMed: 24584118] 
134. Solinas G, Vilcu C, Neels JG, et al. JNK1 in Hematopoietically Derived Cells Contributes to DietInduced Inflammation and Insulin Resistance without Affecting Obesity. Cell Metab. 2007; 6(5): 386-97. [PubMed: 17983584]

135. Fink SL, Cookson BT. Apoptosis, Pyroptosis, and Necrosis: Mechanistic Description of Dead and Dying Eukaryotic Cells. Infect Immun. 2005; 73(4):1907-16. [PubMed: 15784530]

136. Zhou R, Yazdi AS, Menu P, Tschopp J. A role for mitochondria in NLRP3 inflammasome activation. Nature. 2011; 469(7329):221-5. [PubMed: 21124315]

137. Duewell P, Kono H, Rayner KJ, et al. NLRP3 inflammasomes are required for atherogenesis and activated by cholesterol crystals. Nature. 2010; 464(7293):1357-61. [PubMed: 20428172]

138. Wen H, Gris D, Lei Y, et al. Fatty acid-induced NLRP3-ASC inflammasome activation interferes with insulin signaling. Nat Immunol. 2011; 12(5):408-15. [PubMed: 21478880]

139. Chaurasia B, Kaddai VA, Lancaster GI, et al. Adipocyte Ceramides Regulate Subcutaneous Adipose Browning, Inflammation, and Metabolism. Cell Metab. 2016; 24:1-15. [PubMed: 27411001]

140. Vandanmagsar B, Youm Y-H, Ravussin A, et al. The NLRP3 inflammasome instigates obesityinduced inflammation and insulin resistance. Nat Med. 2011; 17(2):179-88. [PubMed: 21217695]

141. Shi H, Kokoeva MV, Inouye K, Tzameli I, Yin H, Flier JS. TLR4 links innate immunity and fatty acid - induced insulin resistance. J Clin Invest. 2006; 116(11):3015-25. [PubMed: 17053832]

142. Lamkanfi M, Mueller JL, Vitari AC, et al. Glyburide inhibits the Cryopyrin/Nalp3 inflammasome. J Cell Biol. 2009; 187(1):61-70. [PubMed: 19805629]

143. Youm Y-H, Nguyen KY, Grant RW, et al. The ketone metabolite $\beta$-hydroxybutyrate blocks NLRP3 inflammasome-mediated inflammatory disease. Nat Med. 2015; 21(3):263-9. [PubMed: 25686106]

144. Coll RC, Robertson AAB, Chae JJ, et al. A small-molecule inhibitor of the NLRP3 inflammasome for the treatment of inflammatory diseases. Nat Med. 2015; 21(3):248-55. [PubMed: 25686105]

145. Groß CJ, Groß O. The Nlrp3 inflammasome admits defeat. Trends Immunol. 2015; 36(6):323-4. [PubMed: 25991463]

146. Liu K, Zhao E, Ilyas G, et al. Impaired macrophage autophagy increases the immune response in obese mice by promoting proinflammatory macrophage polarization. Autophagy. 2015; 11(2): 271-84. [PubMed: 25650776]

147. Saitoh T, Fujita N, Jang MH, et al. Loss of the autophagy protein Atg16L1 enhances endotoxininduced IL-1 $\beta$ production. Nature. 2008; 456(7219):264-8. [PubMed: 18849965]

148. Nakahira K, Haspel JA, Rathinam VAK, et al. Autophagy proteins regulate innate immune response by inhibiting NALP3 inflammasome-mediated mitochondrial DNA release. Nat Immunol. 2011; 12(3):222-30. [PubMed: 21151103]

149. Tanaka M, Matsuo Y, Yamakage H, et al. Differential effects of GLP-1 receptor agonist on foam cell formation in monocytes between non-obese and obese subjects. Metab - Clin Exp. 2017; 65(2):1-11.

150. Marso SP, Daniels GH, Brown-Frandsen K, et al. Liraglutide and Cardiovascular Outcomes in Type 2 Diabetes. N Engl J Med. 2016; 375(4):311-22. [PubMed: 27295427]

151. Marso SP, Bain SC, Consoli A, et al. Semaglutide and Cardiovascular Outcomes in Patients with Type 2 Diabetes. N Engl J Med. 2016; 375(19):1834-44. [PubMed: 27633186]

152. Sinha RA, Singh BK, Yen PM. Reciprocal crosstalk between autophagic and endocrine signaling in metabolic homeostasis. Endocr Rev. 2017; 38(1):69-102. [PubMed: 27901588]

153. Cavalcante-Silva LHA, Galvão JGFM, de F da Silva JS, de Sales-Neto JM, RodriguesMascarenhas S. Obesity-Driven Gut Microbiota Inflammatory Pathways to Metabolic Syndrome. Front Physiol. 2015(6):341.

154. Greer RL, Dong X, Moraes ACF, et al. Akkermansia muciniphila mediates negative effects of IFN $\gamma$ on glucose metabolism. Nat Commun. 2016; 7:13329. [PubMed: 27841267]

155. Skurk T, Alberti-Huber C, Herder C, Hauner H. Relationship between adipocyte size and adipokine expression and secretion. J Clin Endocrinol Metab. 2007; 92(3):1023-33. [PubMed: 17164304] 
156. Arner E, Mejhert N, Kulyté A, et al. Adipose Tissue MicroRNAs as Regulators of CCL2 Production in Human Obesity. Diabetes. 2012; 61(8):1986-93. [PubMed: 22688341]

157. Deng Z, Poliakov A, Hardy RW, et al. Adipose Tissue Exosome-Like Vesicles Mediate Activation of Macrophage-Induced Insulin Resistance. Diabetes. 2009; 58(11):2498-505. [PubMed: 19675137]

158. Norseen J, Hosooka T, Hammarstedt A, et al. Retinol-Binding Protein 4 Inhibits Insulin Signaling in Adipocytes by Inducing Proinflammatory Cytokines in Macrophages through a c-Jun NTerminal Kinase- and Toll-Like Receptor 4-Dependent and Retinol-Independent Mechanism. Mol Cell Biol. 2012; 32(10):2010-9. [PubMed: 22431523]

159. Shen JZ, Morgan J, Tesch GH, et al. Cardiac Tissue Injury and Remodeling Is Dependent Upon MR Regulation of Activation Pathways in Cardiac Tissue Macrophages. Endocrinology. 2016; 157(8):3213-23. [PubMed: 27253999]

160. da Silva SV, Renovato-Martins M, Ribeiro-Pereira C, Citelli M, Barja-Fidalgo C. Obesity modifies bone marrow microenvironment and directs bone marrow mesenchymal cells to adipogenesis. Obesity (Silver Spring). 2016; 24(12):2522-32. [PubMed: 27753270]

161. Nagareddy PR, Kraakman M, Masters SL, et al. Adipose tissue macrophages promote myelopoiesis and monocytosis in obesity. Cell Metab. 2014; 19(5):821-35. [PubMed: 24807222]

162. Amar S, Zhou Q, Shaik-Dasthagirisaheb Y, Leeman S. Diet-induced obesity in mice causes changes in immune responses and bone loss manifested by bacterial challenge. Proc Natl Acad Sci U S A. 2007; 104(51):20466-71. [PubMed: 18077329]

163. Eriksson Hogling D, Petrus P, Gao H, et al. Adipose and Circulating CCL18 Levels Associate With Metabolic Risk Factors in Women. J Clin Endocrinol Metab. 2016; 101(11):4021-29. [PubMed: 27459538]

164. Wittamer V, Franssen J-D, Vulcano M, et al. Specific Recruitment of Antigen-presenting Cells by Chemerin, a Novel Processed Ligand from Human Inflammatory Fluids. J Exp Med. 2003; 198(7):977, 985. [PubMed: 14530373]

165. Ghosh AR, Bhattacharya R, Bhattacharya S, et al. Adipose Recruitment and Activation of Plasmacytoid Dendritic Cells Fuel Metaflammation. Diabetes. 2016; 65(11):3440-52. [PubMed: 27561727]

166. Ernst MC, Sinal CJ. Chemerin: At the crossroads of inflammation and obesity. Trends Endocrinol Metab. 2010; 21(11):660-7. [PubMed: 20817486]

167. Hellmann J, Sansbury BE, Holden CR, et al. CCR7 Maintains Nonresolving Lymph Node and Adipose Inflammation in Obesity. Diabetes. 2016; 65(8):2268-81. [PubMed: 27207557]

168. Pirvulescu MM, Gan AM, Stan D, et al. Subendothelial resistin enhances monocyte transmigration in a co-culture of human endothelial and smooth muscle cells by mechanisms involving fractalkine, MCP-1 and activation of TLR4 and Gi/o proteins signaling. Int J Biochem Cell Biol. 2014; 50:29-37. [PubMed: 24508784]

169. Kanda H, Tateya S, Tamori Y, et al. MCP-1 contributes to macrophage infiltration into adipose tissue, insulin resistance, and hepatic steatosis in obesity. J Clin Invest. 2006; 116(6):1494-505. [PubMed: 16691291]

170. Alfaradhi MZ, Kusinski LC, Fernandez-Twinn DS, et al. Maternal Obesity in Pregnancy Developmentally Programs Adipose Tissue Inflammation in Young, Lean Male Mice Offspring. Endocrinology. 2016; 157(11):4246-56. [PubMed: 27583789]

171. Bruun JM, Lihn AS, Pedersen SB, Richelsen B. Monocyte Chemoattractant Protein-1 Release Is Higher in Visceral than Subcutaneous Human Adipose Tissue (AT): Implication of Macrophages Resident in the AT. J Clin Endocrinol Metab. 2005; 90(4):2282-9. [PubMed: 15671098]

172. Krysiak R, Okopien B. The effect of metformin on monocyte secretory function in simvastatintreated patients with impaired fasting glucose. Metab - Clin Exp. 2017; 62(1):39-43.

173. Cinti S, Mitchell G, Barbatelli G, et al. Adipocyte death defines macrophage localization and function in adipose tissue of obese mice and humans. J Lipid Res. 2005; 46(11):2347-55. [PubMed: 16150820]

174. Cancello R, Tordjman J, Poitou C, et al. Increased Infiltration of Macrophages in Omental Adipose Tissue Is Associated With Marked Hepatic Lesions in Morbid Human Obesity. Diabetes. 2006; 55(6):1554-61. [PubMed: 16731817] 
175. Huang ZH, Manickam B, Ryvkin V, et al. PCOS Is Associated with Increased CD11c Expression and Crown-Like Structures in Adipose Tissue and Increased Central Abdominal Fat Depots Independent of Obesity. J Clin Endocrinol Metab. 2012; 98(1):E17-24. [PubMed: 23118428]

176. Bañuls, C., Rovira-Llopis, S., de Marañon, AM., et al. Metabolic syndrome enhances endoplasmic reticulum, oxidative stress and leukocyte-endothelium interactions in PCOS. Metab - Clin Exp. 2017. (early release). http://dx.doi.org/10.1016/j.metabol.2017.02.012

177. Haczeyni F, Poekes L, Wang H, et al. Obeticholic acid improves adipose morphometry and inflammation and reduces steatosis in dietary but not metabolic obesity in mice. Obesity. 2017; 25(1):155-165. [PubMed: 27804232]

178. McDonnell ME, Ganley-Leal LM, Mehta A, et al. B Lymphocytes in Human Subcutaneous Adipose Crown-Like Structures. Obesity. 2012; 20(7):1372-8. [PubMed: 22395812]

179. Zhu M, Belkina AC, Defuria J, et al. B cells promote obesity-associated periodontitis and oral pathogen-associated inflammation. J Leukoc Biol. 2014; 5(96):349-57.

180. DeFuria J, Belkina AC, Jagannathan-Bogdan M, et al. B cells promote inflammation in obesity and type 2 diabetes through regulation of T-cell function and an inflammatory cytokine profile. Proc Natl Acad Sci U S A. 2013; 110(13):5133-8. [PubMed: 23479618]

181. Winer DA, Winer S, Shen L, et al. B cells promote insulin resistance through modulation of T cells and production of pathogenic IgG antibodies. Nat Med. 2011; 17(5):610-7. [PubMed: 21499269]

182. Ip B, Cilfone NA, Belkina AC, et al. Th17 cytokines differentiate obesity from obesity-associated type 2 diabetes and promote TNFa production. Obesity. 2016; 24(1):102-12. [PubMed: 26576827]

183. Nishimura S, Manabe I, Nagasaki M, et al. CD8+ effector T cells contribute to macrophage recruitment and adipose tissue inflammation in obesity. Nat Med. 2009; 15(8):914-20. [PubMed: 19633658]

184. Poggi M, Engel D, Christ A, et al. CD40L Deficiency Ameliorates Adipose Tissue Inflammation and Metabolic Manifestations of Obesity in Mice. Arterioscler Thromb Vasc Biol. 2011; 31(10): 2251-60. [PubMed: 21817098]

185. Magalhaes I, Pingris K, Poitou C, et al. Mucosal-associated invariant T cell alterations in obese and type 2 diabetic patients. J Clin Invest. 2015; 125(4):1752-62a. [PubMed: 25751065]

186. Santalahti K, Maksimow M, Airola A, et al. Circulating Cytokines Predict the Development of Insulin Resistance in a Prospective Finnish Population Cohort. J Clin Endocrinol Metab. 2016; 101(9):3361-69. [PubMed: 27362289]

187. Jagannathan-Bogdan M, McDonnell ME, Shin H, et al. Elevated Proinflammatory Cytokine Production by a Skewed T Cell Compartment Requires Monocytes and Promotes Inflammation in Type 2 Diabetes. J Immunol. 2010; 186(2):1162-72. [PubMed: 21169542]

188. Tiemessen MM, Jagger AL, Evans HG, van Herwijnen MJC, John S, Taams LS. CD4+CD25+Foxp3+ regulatory $\mathrm{T}$ cells induce alternative activation of human monocytes/ macrophages. Proc Natl Acad Sci U S A. 2007; 104(49):19446-51. [PubMed: 18042719]

189. Lee B-C, Kim M-S, Pae M, et al. Adipose Natural Killer Cells Regulate Adipose Tissue Macrophages to Promote Insulin Resistance in Obesity. Cell Metab. 2016:685-98.

190. Bertola A, Deveaux V, Bonnafous S, et al. Elevated Expression of Osteopontin May Be Related to Adipose Tissue Macrophage Accumulation and Liver Steatosis in Morbid Obesity. Diabetes. 2008; 58(1):125-33. [PubMed: 18952835]

191. Shirakawa K, Yan X, Shinmura K, et al. Obesity accelerates T cell senescence in murine visceral adipose tissue. J Clin Invest. 126(12):4626-39.

192. Nikolajczyk BS, Jagannathan-Bogdan M, Shin H, Gyurko R. State of the union between metabolism and the immune system in type 2 diabetes. Genes Immun. 2011; 12(4):239-50. [PubMed: 21390053]

193. Blüher M. Adipose tissue inflammation: a cause or consequence of obesity-related insulin resistance? Clin Sci. 2016; 130:1603-14. [PubMed: 27503945]

194. Pasarica M, Sereda OR, Redman LM, et al. Reduced Adipose Tissue Oxygenation in Human Obesity. Diabetes. 2009; 58(3):718-25. [PubMed: 19074987] 
195. Choe SS, Huh JY, Hwang IJ, Kim JI, Kim JB. Adipose tissue remodeling: Its role in energy metabolism and metabolic disorders. Front Endocrinol (Lausanne). 2016 Apr.7

196. Takikawa A, Mahmood A, Nawaz A, et al. HIF-1a in Myeloid Cells Promotes Adipose Tissue Remodeling Toward Insulin Resistance. Diabetes. 2016; 65(12):3649-59. [PubMed: 27625023]

197. Rydén M, Andersson DP, Bergström IB, Arner P. Adipose Tissue and Metabolic Alterations: Regional Differences in Fat Cell Size and Number Matter, But Differently: A Cross-Sectional Study. J Clin Endocrinol Metab. 2014; 99(10):E1870-6. [PubMed: 24937536]

198. Rodríguez A, Ezquerro S, Méndez-Giménez L, Becerril SFG. Revisiting the adipocyte: a model for integration of cytokine signaling in the regulation of energy metabolism. Am J Physiol Endocrinol Metab. 2015; 309(8):E691-E714. DOI: 10.1152/ajpendo.00297.2015 [PubMed: 26330344]

199. O'Hara A, Lim FL, Mazzatti DJ, Trayhurn P. Stimulation of inflammatory gene expression in human preadipocytes by macrophage-conditioned medium: Upregulation of IL-6 production by macrophage-derived IL-1 $\beta$. Mol Cell Endocrinol. 2012; 349(2):239-247. [PubMed: 22079434]

200. O'Hara A, Lim FL, Mazzatti DJ, Trayhurn P. Microarray analysis identifies matrix metalloproteinases (MMPs) as key genes whose expression is up-regulated in human adipocytes by macrophage-conditioned medium. Pflugers Arch Eur J Physiol. 2009; 458(6):1103-14. [PubMed: 19585142]

201. Catalá V, Gómez-Ambrosi J, Rodríguez A, et al. Increased tenascin C and toll-like receptor 4 levels in visceral adipose tissue as a link between inflammation and extracellular matrix remodeling in obesity. J Clin Endocrinol Metab. 2012; 97(10)doi: 10.1210/jc.2012-1670

202. Spencer M, Yao-Borengasser A, Unal R, et al. Adipose tissue macrophages in insulin-resistant subjects are associated with collagen VI and fibrosis and demonstrate alternative activation. Am J Physiol Endocrinol Metab. 2010; 299(6):E1016-E1027. [PubMed: 20841504]

203. Sun K, Kusminski CM, Scherer PE. Adipose tissue remodeling and obesity. J Clin Invest. 121(6): 2094-101.

204. Sun K, Park J, Gupta OT, et al. Endotrophin triggers adipose tissue fibrosis and metabolic dysfunction. Nat Commun. 2014; 5(3485):1-12.

205. Luo T, Nocon A, Fry J, et al. AMPK Activation by Metformin Suppresses Abnormal Extracellular Matrix Remodeling in Adipose Tissue and Ameliorates Insulin Resistance in Obesity. Diabetes. 2016; 65(8):2295-2310. [PubMed: 27207538]

206. Alcalá M, Sánchez-Vera I, Sevillano J, et al. Vitamin E reduces adipose tissue fibrosis, inflammation, and oxidative stress and improves metabolic profile in obesity. Obesity. 2015; 23(8):1598-606. [PubMed: 26148343]

207. Fang F, Liu L, Yang Y, et al. The adipokine adiponectin has potent anti-fibrotic effects mediated via adenosine monophosphate-activated protein kinase: novel target for fibrosis therapy. Arthritis Res Ther. 2012; 14(5):R229. [PubMed: 23092446]

208. Baker NA, Muir LA, Washabaugh AR, et al. Diabetes-Specific Regulation of Adipocyte Metabolism by the Adipose Tissue Extracellular Matrix. J Clin Endocrinol Metab. 2017; 102(3): 1032-43. [PubMed: 28359093]

209. Keophiphath M, Achard V, Henegar C, Rouault C, Clément K, Lacasa D. Macrophage-secreted factors promote a profibrotic phenotype in human preadipocytes. Mol Endocrinol. 2009; 23(1): 11-24. DOI: 10.1210/me.2008-0183 [PubMed: 18945811]

210. Sun K, Tordjman J, Clément K, Scherer PE. Fibrosis and Adipose Tissue Dysfunction. Cell Metab. 2013; 18(4):470-7. [PubMed: 23954640]

211. Muir LA, Neeley CK, Meyer KA, et al. Adipose tissue fibrosis, hypertrophy, and hyperplasia: Correlations with diabetes in human obesity. Obesity. 2016; 24(3):597-605. [PubMed: 26916240]

212. Creely SJ, McTernan PG, Kusminski CM, et al. Lipopolysaccharide activates an innate immune system response in human adipose tissue in obesity and type 2 diabetes. Am J Physiol Endocrinol Metab. 2007; 292(3):E740-E747. [PubMed: 17090751]

213. Reddy MA, Chen Z, Park JT, et al. Regulation of inflammatory phenotype in macrophages by a diabetes-induced long noncoding RNA. Diabetes. 2014; 63(12):4249-61. [PubMed: 25008173] 
214. Belkina AC, Nikolajczyk BS, Denis GV. BET protein function is required for inflammation: Brd2 genetic disruption and BET inhibitor JQ1 impair mouse macrophage inflammatory responses. J Immunol. 2013; 190(7):3670-3678. [PubMed: 23420887]

215. Meng S, Zhang L, Tang Y, et al. BET Inhibitor JQ1 Blocks Inflammation and Bone Destruction. J Dent Res. 2014; 93(7):657-62. [PubMed: 24799421]

216. Kallio KAE, Hyvärinen K, Kovanen PT, Jauhiainen M, Pussinen PJ. Very low density lipoproteins derived from periodontitis patients facilitate macrophage activation via lipopolysaccharide function. Metab - Clin Exp. 2017; 62(5):661-8.

217. Fan B, Gu J-Q, Yan R, Zhang H, Feng J, Ikuyama S. High glucose, insulin and free fatty acid concentrations synergistically enhance perilipin 3 expression and lipid accumulation in macrophages. Metab - Clin Exp. 2017; 62(8):1168-79.

218. Jansen HJ, Stienstra R, van Diepen JA, et al. Start of insulin therapy in patients with type 2 diabetes mellitus promotes the influx of macrophages into subcutaneous adipose tissue. Diabetologia. 2013; 56(12):2573-81. [PubMed: 24065152]

219. Pedersen DJ, Guilherme A, Danai LV, et al. A major role of insulin in promoting obesityassociated adipose tissue inflammation. Mol Metab. 2015; 4(7):507-18. [PubMed: 26137438]

220. Dandona P, Aljada A, Mohanty P, et al. Insulin Inhibits Intranuclear Nuclear Factor $\kappa \mathrm{B}$ and Stimulates I $\mathrm{KB}$ in Mononuclear Cells in Obese Subjects: Evidence for an Anti-inflammatory Effect? J Clin Endocrinol Metab. 2001; 86(7):3257-65. [PubMed: 11443198]

221. Cochran BJ, Hou L, Chirackal Manavalan AP, et al. Impact of Perturbed Pancreatic $\beta$-cell Cholesterol Homeostasis on Adipose Tissue and Skeletal Muscle Metabolism. Diabetes. 2016; (12):3610-3620. [PubMed: 27702832]

222. Donath MY. Targeting inflammation in the treatment of type 2 diabetes. Diabetes Obes Metab. 2013; 15(Suppl 3):193-6.

223. Sullivan T, Miao Z, Dairaghi DJ, et al. CCR2 antagonist CCX140-B provides renal and glycemic benefits in diabetic transgenic human CCR2 knockin mice. Am J Physiol - Ren Physiol. 2013; 305(9):F1288-97.

224. Sullivan TJ, Miao Z, Zhao BN, et al. Experimental evidence for the use of CCR2 antagonists in the treatment of type 2 diabetes. Metab - Clin Exp. 2017; 62(11):1623-32.

225. de Zeeuw D, Bekker P, Henkel E, et al. The effect of CCR2 inhibitor CCX140-B on residual albuminuria in patients with type 2 diabetes and nephropathy: a randomised trial. Lancet Diabetes Endocrinol. 2015; 3(9):687-96. [PubMed: 26268910]

226. Larsen CM, Faulenbach M, Vaag A, Ehses JA, Donath MY, Mandrup-Poulsen T. Sustained effects of interleukin-1 receptor antagonist treatment in type 2 diabetes. Diabetes Care. 2009; 32(9): 1663-68. [PubMed: 19542207]

227. Ridker PM, Howard CP, Walter V, et al. Effects of Interleukin- $1 \beta$ Inhibition With Canakinumab on Hemoglobin A1c, Lipids, C-Reactive Protein, Interleukin-6, and Fibrinogen. Circulation. 2012; 126(23):2739-48. [PubMed: 23129601]

228. Wernstedt Asterholm I, Tao C, Morley TS, et al. Adipocyte Inflammation Is Essential for Healthy Adipose Tissue Expansion and Remodeling. Cell Metab. 2014; 20(1):103-18. [PubMed: 24930973]

229. Goh J, Goh KP, Abbasi A. Exercise and Adipose Tissue Macrophages: New Frontiers in Obesity Research? Front Endocrinol. 2016; 7:65.

230. Gleeson M, Bishop NC, Stensel DJ, Lindley MR, Mastana SS, Nimmo Ma. The antiinflammatory effects of exercise: mechanisms and implications for the prevention and treatment of disease. Nat Rev Immunol. 2011; 11(9):607-15. [PubMed: 21818123]

231. Mauer J, Chaurasia B, Goldau J, et al. Signaling by IL-6 promotes alternative activation of macrophages to limit endotoxemia and obesity-associated resistance to insulin. Nat Immunol. 2014; 15(5):423-30. [PubMed: 24681566]

232. Febbraio MA. Role of interleukins in obesity: implications for metabolic disease. Trends Endocrinol Metab. 2014; 25(6):312-9. [PubMed: 24698032]

233. Zoppini G, Targher G, Zamboni C, et al. Effects of moderate-intensity exercise training on plasma biomarkers of inflammation and endothelial dysfunction in older patients with type 2 diabetes. Nutr Metab Cardiovasc Dis. 2016; 16(8):543-9. 
234. Lyons CL, Kennedy EB, Roche HM. Metabolic inflammation-differential modulation by dietary constituents. Nutrients. 2016; 8(5)

235. Lopez-Legarrea P, de la Iglesia R, Abete I, Navas-Carretero S, Martinez JA, Zulet MA. The protein type within a hypocaloric diet affects obesity-related inflammation: The RESMENA project. Nutrition. 2014; 30(4):424-9. [PubMed: 24607301]

236. van Dijk SJ, Feskens EJM, Bos MB, et al. A saturated fatty acid-rich diet induces an obesitylinked proinflammatory gene expression profile in adipose tissue of subjects at risk of metabolic syndrome. Am J Clin Nutr. 2009; 90(6):1656-64. [PubMed: 19828712]

237. Ghanim H, Abuaysheh S, Sia CL, et al. Increase in Plasma Endotoxin Concentrations and the Expression of Toll-Like Receptors and Suppressor of Cytokine Signaling-3 in Mononuclear Cells After a High-Fat, High-Carbohydrate Meal. Diabetes Care. 2009; 32(12):2281-87. [PubMed: 19755625]

238. Ghanim H, Sia CL, Upadhyay M, et al. Orange juice neutralizes the proinflammatory effect of a high-fat, high-carbohydrate meal and prevents endotoxin increase and Toll-like receptor expression. Am J Clin Nutr. 2010; 91(4):940-9. [PubMed: 20200256]

239. Ghanim H, Batra M, Abuaysheh S, et al. Antiinflammatory and ROS Suppressive Effects of the Addition of Fiber to a High-Fat High-Calorie Meal. J Clin Endocrinol Metab. 2017; 102(3):85869. [PubMed: 27906549]

240. Ruth MR, Port AM, Shah M, et al. Consuming a hypocaloric high fat low carbohydrate diet for 12 weeks lowers C-reactive protein, and raises serum adiponectin and high density lipoproteincholesterol in obese subjects. Metab - Clin Exp. 2016; 62(12):1779-87.

241. Oh DY, Talukdar S, Bae EJ, et al. GPR120 Is an Omega-3 Fatty Acid Receptor Mediating Potent Anti-inflammatory and Insulin-Sensitizing Effects. Cell. 2010; 142(5):687-98. [PubMed: 20813258]

242. Kalupahana NS, Claycombe K, Newman SJ, et al. Eicosapentaenoic acid prevents and reverses insulin resistance in high-fat diet-induced obese mice via modulation of adipose tissue inflammation. J Nutr. 2010; 140(11):1915-22. [PubMed: 20861209]

243. Spencer M, Finlin BS, Unal R, et al. Omega-3 Fatty Acids Reduce Adipose Tissue Macrophages in Human Subjects With Insulin Resistance. Diabetes. 2013; 62(5):1709-17. [PubMed: 23328126]

244. Hellmann J, Tang Y, Kosuri M, Bhatnagar A, Spite M. Resolvin D1 decreases adipose tissue macrophage accumulation and improves insulin sensitivity in obese-diabetic mice. FASEB J. 2011; 25(7):2399-407. [PubMed: 21478260]

245. Šrámková V, Rossmeislová L, Krauzová E, et al. Comparison of Early (2 Days) and Later (28 Days) Response of Adipose Tissue to Very Low-Calorie Diet in Obese Women. J Clin Endocrinol Metab. 2016; 101(12):5021-29. [PubMed: 27715401]

246. Kovacikova M, Sengenes C, Kovacova Z, et al. Dietary intervention-induced weight loss decreases macrophage content in adipose tissue of obese women. Int J Obes. 2011; 35(1):91-8.

247. Hafida S, Mirshahi T, Nikolajczyk BS. The impact of bariatric surgery on inflammation: quenching the fire of obesity? Curr Opin Endocrinol Diabetes Obes. 2016; 23(5):373-8. [PubMed: 27455515]

248. Moreno-Indias I, Oliva-Olivera W, Omiste A, et al. Adipose tissue infiltration in normal-weight subjects and its impact on metabolic function. Transl Res. 2016; 172:6-17. [PubMed: 26829067]

249. Kratz M, Hagman DK, Kuzma JN, et al. Improvements in glycemic control after gastric bypass occur despite persistent adipose tissue inflammation. Obesity. 2016; 24(7):1438-45. [PubMed: 27228052]

250. Aron-Wisnewsky J, Tordjman J, Poitou C, et al. Human adipose tissue macrophages: M1 and M2 cell surface markers in subcutaneous and omental depots and after weight loss. J Clin Endocrinol Metab. 2009; 94(11):4619-23. [PubMed: 19837929]

251. Catalán V, Gómez-Ambrosi J, Rodríguez A, et al. Increased IL-32 Levels in Obesity Promote Adipose Tissue Inflammation and Extracellular Matrix Remodeling. Effect of Weight Loss. Diabetes. 2016; 65(12):3636-48. [PubMed: 27630206] 
252. Andersson DP, Thorell A, Löfgren P, et al. Omentectomy in addition to gastric bypass surgery and influence on insulin sensitivity: A randomized double blind controlled trial. Clin Nutr. 2014; 33(6):991-6. [PubMed: 24485000]

253. Goktas Z, Moustaid-Moussa N, Shen C-L, Boylan M, Mo H, Wang S. Effects of Bariatric Surgery on Adipokine-Induced Inflammation and Insulin Resistance. Front Endocrinol (Lausanne). 2013; 4:69. [PubMed: 23772224]

254. Athyros VG, Alexandrides TK, Bilianou H, et al. The use of statins alone, or in combination with pioglitazone and other drugs, for the treatment of non-alcoholic fatty liver disease/non-alcoholic steatohepatitis and related cardiovascular risk. An Expert Panel Statement. Metab - Clin Exp. 2017; 71:17-32. [PubMed: 28521870] 

Lean adipose tissue
Obesity and metabolic syndrome
Diabetes

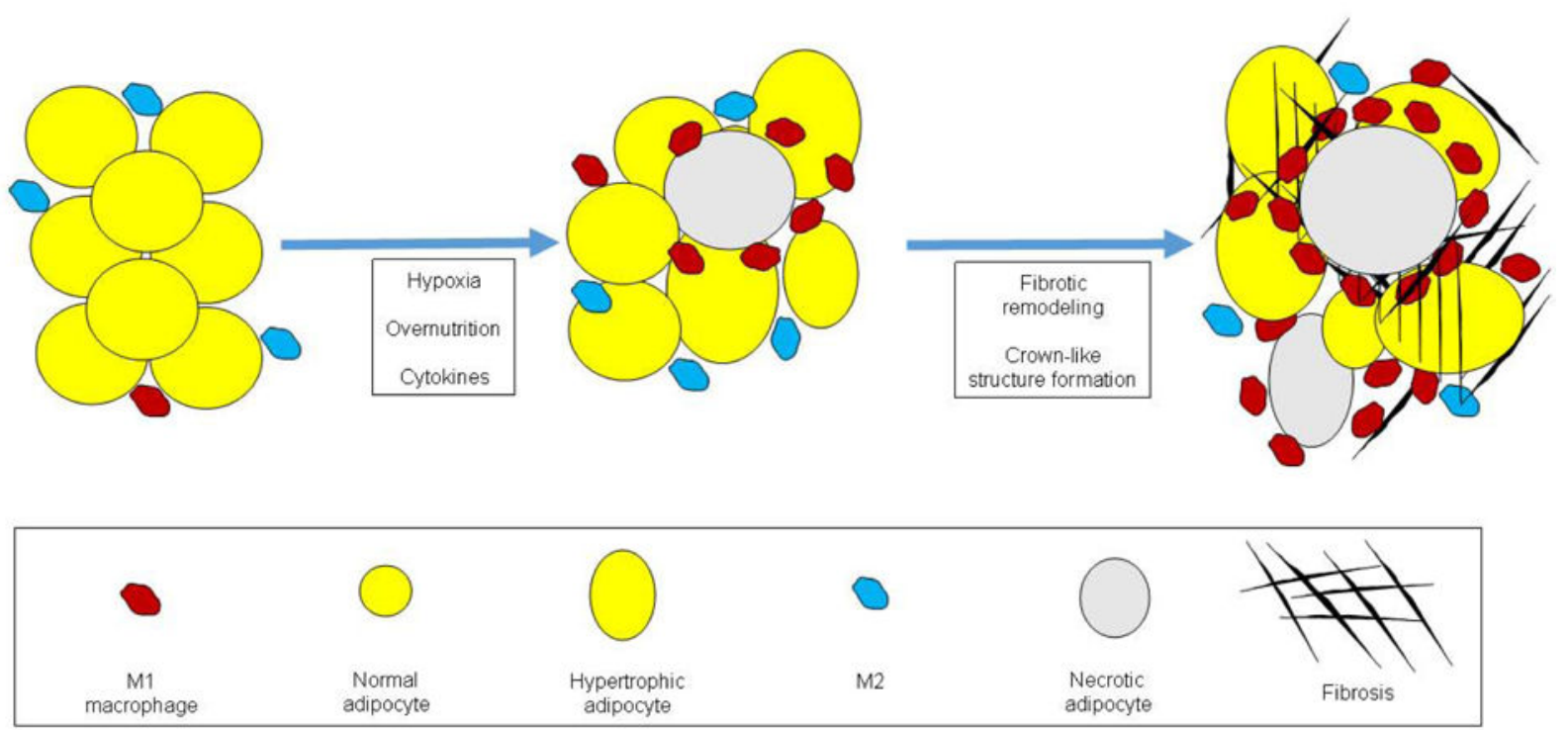

Figure 1.

Monocyte differentiation into adipose tissue M1 and M2 macrophages is regulated by cytokines and adipokines. 


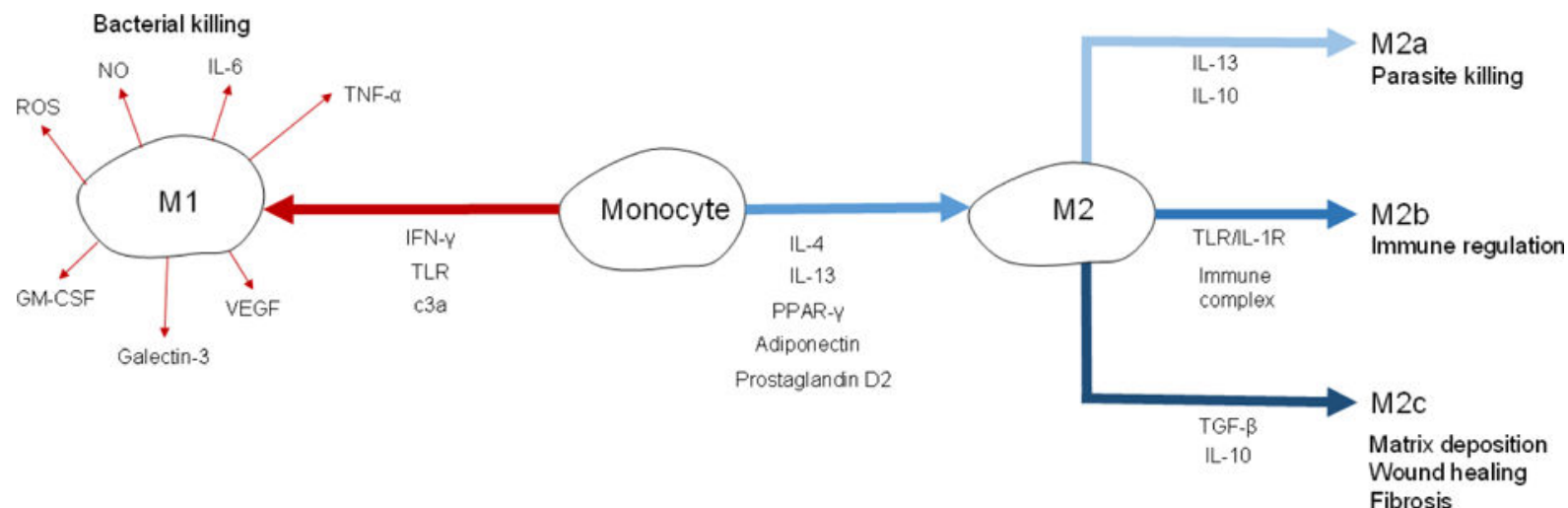

Figure 2.

Macrophage infiltration during obesity is associated with hypoxia and increased M1 activation with adipocyte necrosis and crown-like structure formation that results in adipose tissue fibrosis. 


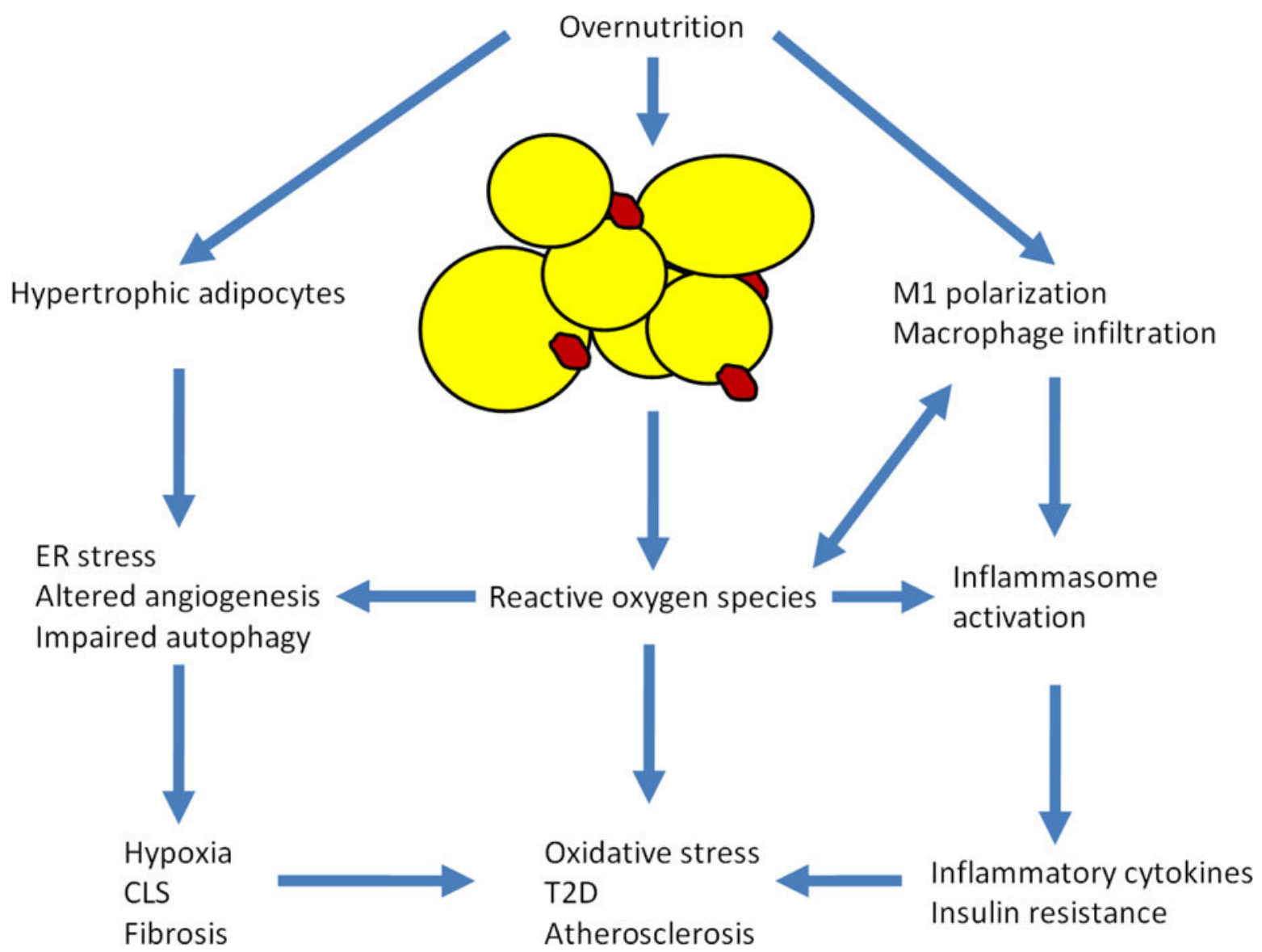

Figure 3.

Consequences of overnutrition on adipose tissue, inflammation, and metabolism 
Table 1

Comparison of key characteristics of M1 and M2 macrophages.

\begin{tabular}{|c|c|c|}
\hline & M1 & M2 \\
\hline Markers & F4/80, CD11b, and CD11c; CD86; CD32; CCR7 & F4/80, CD11b; CD301; Arg1; CD206 \\
\hline Functions & $\begin{array}{l}\text { Production of reactive oxygen species for bacterial } \\
\text { killing }\end{array}$ & $\begin{array}{l}\text { Promotion of preadipocyte survival, wound healing, } \\
\text { resolution of inflammation }\end{array}$ \\
\hline Secreted factors & Galectin-3, resistin; IL-1; IL-18; IL-6; TNF-a & IL-10, IL-1RA, TGF- $\beta$, Protectin \\
\hline Induced by & $\begin{array}{l}\text { IFN- } \gamma \\
\text { TLR4 } \\
\text { Saturated FFA } \\
\text { Aldosterone } \\
\text { LTB4 } \\
\text { Ceramides } \\
\text { Type I interferons } \\
\text { PAMP/DAMP } \\
\text { LPS }\end{array}$ & $\begin{array}{l}\text { Prostaglandin D2 } \\
\text { IL-4 } \\
\text { Meteorin-like } \\
\text { Adiponectin } \\
\text { IL-10 } \\
\text { IL-13 } \\
\text { T regulatory cells } \\
\text { Eosinophils } \\
\text { FAHFA } \\
\text { AMPK }\end{array}$ \\
\hline Metabolic effects & $\begin{array}{l}\text { Promote insulin resistance } \\
\text { Decrease UCP1 }\end{array}$ & $\begin{array}{l}\text { Promote insulin sensitivity } \\
\text { Increase UCP1 } \\
\text { Promote mitochondrial health }\end{array}$ \\
\hline Metabolism & Glycolysis & Oxidative phosphorylation \\
\hline Dominant polarization & Obese adipose tissue & Lean adipose tissue \\
\hline
\end{tabular}




\section{Table 2}

Comparison of key characteristics of PPAR families.

\begin{tabular}{|l|l|l|l|}
\hline & PPAR-a & PPAR- $\delta$ & PPAR- $\gamma$ \\
\hline Agonists & $\begin{array}{l}\text { DHEA-S } \\
\text { Gemfibrozil } \\
\text { Fenofibrate }\end{array}$ & $\begin{array}{l}\text { Bezafibrate } \\
\text { Apoptotic cells }\end{array}$ & $\begin{array}{l}\text { TZD } \\
\text { Meteorin-like }\end{array}$ \\
\hline Metabolic effects & $\begin{array}{l}\text { Promotes fatty acid utilization by liver } \\
\text { and ketogenesis } \\
\text { Activates FGF21 Insulin sensitizing }\end{array}$ & $\begin{array}{l}\text { Promotes fatty acid utilization by muscle and } \\
\text { liver } \\
\text { Insulin sensitizing }\end{array}$ & $\begin{array}{l}\text { Fatty acid metabolism } \\
\text { Mitochondrial biogenesis } \\
\text { Adipogenesis } \\
\text { Insulin sensitizing } \\
\text { Increases adiponectin }\end{array}$ \\
\hline Inflammatory effects & Inhibits NFKB & $\begin{array}{l}\text { Required for M2 differentiation } \\
\text { Enhances opsonin production }\end{array}$ & $\begin{array}{l}\text { Inhibits NFKB } \\
\text { M2 polarizing }\end{array}$ \\
\hline
\end{tabular}

